\title{
Initial Study of Controller/Automation Integration for NextGen Separation Assurance
}

\author{
Thomas Prevot ${ }^{1}$, Jeffrey Homola ${ }^{2}$ and Joey Mercer ${ }^{3}$ \\ San Jose State University/NASA Ames Research Center, Moffett Field, CA, 94035
}

\begin{abstract}
This paper describes an initial human-in-the-loop part-task study on service providerbased automated separation assurance for the Next Generation Air Transportation System (NextGen). The study varied levels of trajectory-based separation assurance automation from manual trial planning to fully automated conflict resolution over $1 x, 2 x$ and $3 x$ traffic densities. The experiment was conducted in the Airspace Operations Laboratory at NASA Ames Research Center in August 2007. In this study envisioned trajectory based operations for the NextGen were simulated. The ground-side automation was responsible for conflict detection. Four recently retired air traffic controllers and five aviation knowledgeable students participated and were responsible for resolving potential conflicts between aircraft with varying levels of automation. Two combined sectors engaged participants in solving conflicts between an average of $30(1 x), 60(2 x)$, and $90(3 x)$ aircraft during the 30 minute long simulation runs, resulting in approximately $6(1 \mathrm{x}), 42(2 \mathrm{x})$ and $90(3 \mathrm{x})$ conflicts per run. The within subjects design gave operators access to a fast manual trial planning function in half the human-in-the-loop runs. During the other half of the runs participants could also interact with the advanced airspace concepts' conflict resolution algorithm developed at NASA Ames Research Center. The controllers could use the algorithm to request a conflict resolution trajectory and uplink it unchanged, modify the resolution trajectory using the trial planner and then uplink it, or cancel the modification. The analysis shows that in the simulated part-task setting the $2 x$ density was very manageable and adequate for the interactive mode and was somewhat manageable with a manual trial planner. $3 x$ density was somewhat manageable interactively, but would not pass the "spill your coffee" test. 3x density was unmanageable using the trial planning function alone and resulted in many separation violations. Objective and subjective data indicate that the conflict resolution automation was highly acceptable across traffic levels and provided efficient trajectory changes at high traffic densities. The conflict resolution automation reduced the average and the peak workload significantly. In this paper the problem, method, and key findings will be presented. This research is an initial step towards addressing the challenges associated with human/system integration for ground-based NextGen separation assurance and was funded by the Separation Assurance element of NASA's Next Generation Air Transportation Airspace Project.
\end{abstract}

\section{Nomenclature}

$A A C=$ Advanced Airspace Concept

$A C E S=$ Airspace Concept Evaluation System

$A D S-A / B=$ Automatic Dependent Surveillance-Addressed/Broadcast

$A D R S=$ Aeronautical Data Link and Radar Simulator

$A O L=$ Airspace Operations Laboratory (at NASA Ames Research Center)

\footnotetext{
${ }^{1}$ Senior Research Engineer, Human Systems Integration Division NASA Ames, MS 262-4, AIAA member.

${ }^{2}$ Research Associate, Human Systems Integration Division, NASA Ames, MS 262-4.. AIAA member.

${ }^{3}$ Research Associate, Human Systems Integration Division, NASA Ames, MS 262-4.. AIAA member.
} 


$\begin{array}{ll}A S A S & =\text { Airborne Separation Assistance System } \\ A T M & =\text { Air Traffic Management } \\ A T S P & =\text { Air Traffic Service Providers } \\ C D T I & =\text { Cockpit Display of Traffic Information } \\ C P D L C & =\text { Controller Pilot Data Link Communication } \\ C T A S & =\text { Center/TRACON Automation System } \\ D A G-T M & =\text { Distributed Air Ground Traffic Management } \\ D A C & =\text { Dynamic Airspace Configuration } \\ D S R & =\text { Display System Replacement (En Route Controller Workstation in the NAS) } \\ D S T & =\text { Decision Support Tool } \\ F A A & =\text { Federal Aviation Administration } \\ F M S & =\text { Flight Management System } \\ I F R & =\text { Instrument Flight Rules } \\ M A C S & =\text { Multi Aircraft Control System } \\ N A S & =\text { National Airspace System } \\ N A S A & =\text { National Aeronautics and Space Administration } \\ N e x t G e n & =\text { Next Generation Air Transportation System } \\ T F R & =\text { Trajectory-based Flight Rules } \\ T M A & =\text { Traffic Management Advisor } \\ T R A C O N & =\text { Terminal RADAR Approach Control } \\ T S A F E & =\text { Tactical Separation Assisted Flight Environment } \\ R N P & =\text { Required Navigation Performance } \\ R V S M & =\text { Reduced Vertical Separation Minima } \\ S A & =\text { Separation Assurance } \\ S E S A R & =\text { Single European Sky ATM Research program }\end{array}$

\section{Introduction}

A ir traffic demand is anticipated to grow substantially in the coming decades ${ }^{1}$. The Federal Aviation Administration (FAA) and industry forecast that air traffic operations are expected to increase 150 to 250 percent over the next two decades. Analysis of even the most conservative growth estimate shows a significant lack of existing and planned capacity to meet the demand. ${ }^{2}$

The Joint Planning and Development Office (JPDO) has been established to transform the U.S. air transportation system by 2025. According to JPDO, the Next Generation Air Transportation System (NextGen) will be more flexible, resilient, scalable, adaptive, and highly automated than today's system - meeting up to two to three times current demand. The NextGen includes security, safety, and efficiency of passenger, cargo and aircraft operations. Aircraft will be able to use information technology in a more robust way, with enhanced capabilities in the cockpit, better navigation and landing capabilities, and far more comprehensive and accurate knowledge of weather and traffic conditions in real time. ${ }^{3,4}$

Similarly, the European Commission (EC) launched the Single European Sky ATM Research (SESAR) program, to achieve a future European ATM System for 2020 and beyond, which can meet the following objectives: Relative to today's performance enable a 3-fold increase in capacity while also reducing delays both on the ground and in the air; Improve the safety performance by a factor of 10; enable a 10\% reduction in the environmental effects; And provide ATM services at a cost to the airspace users which is at least $50 \%$ less. ${ }^{5}$

Both initiatives, NextGen and SESAR, aim at drastic air traffic system improvements that can at least double capacity in the next twenty years. Fundamental laboratory research is required to define and develop a transformed system that can meet these objectives. The primary focus of the NASA NextGen ATM-Airspace project is to explore and develop integrated solutions providing research data to define and assess the allocation of ground and air automation concepts and technologies including the human roles necessary for the NextGen. ${ }^{6}$

The research described in this paper is funded under the Separation Assurance element of the NASA NGATS ATM-Airspace project and directly addresses the project milestone (AS 2.5.03) entitled "Initial service-providerbased automated separation assurance simulation". ${ }^{6}$ As expected in the metrics for this milestone the initial 
simulation and the laboratory capability that was created for the study provides an opportunity for researchers and stakeholders to gain initial insight and provide initial feedback by viewing the operating concept with humans in the loop. While the initial objective analysis focuses on nominal operations it can start informing concepts and analysis for failure recovery operations as well. The study also starts evaluating the methods for gathering and analyzing experimental data during human in the loop simulations.

The scenarios are based upon scenarios used during a 2006 full mission simulation of Trajectory-Oriented Operations with Limited Delegation (TOOWiLD) ${ }^{7}$ within the same airspace at NASA Ames Research Center. The TOOWiLD data serve as a baseline for simulated current day operations to compare and contrast to the results gathered in the part-task study described in this paper which was also conducted in the Airspace Operations Laboratory $(\mathrm{AOL})^{8}$. It is complemented with air-side experiments in the Flight Deck Display Research Laboratory $(\text { FDDRL) })^{9}$ that investigate conflict resolution strategies from a flight deck perspective.

Common goals are to assess strengths and weaknesses of automated, controller and pilot generated resolutions and provide preliminary guidance for the integration of automated resolutions and resolution advisories into ATM systems.

\section{Problem}

The primary purpose of this research is to gather more insight into the fundamental problem of human/automation integration and allocation of roles and responsibilities required to achieve the significant capacity increases targeted for the NextGen. The part task study described in this paper specifically begins to investigate the future role of air traffic controllers and automation in a service provider-based automated separation assurance environment. The focus is on trajectory-based operations at substantially higher traffic densities than in today's airspace system.

It is assumed that managing 2 or 3 times today's traffic density requires a fundamental change from today's operations in how separation between aircraft is assured. In today's very safe system, air traffic controllers take active control over each aircraft in their airspace and issue clearances to keep it separate from other traffic, expedite traffic flows, and provide additional services, workload permitting. Being actively involved with each individual aircraft provides the awareness required to detect and resolve potential losses of separation independent of automated aids. However, this manual process can only be performed for a very limited number of aircraft. In recognition of this fact, each airspace sector today has a defined maximum number of aircraft that are allowed to enter. This constraint exists as a way of ensuring that the demands on the cognitive resources of the air traffic controller(s) controlling this sector are not exceeded.

NextGen envisions trajectory-based operations (TBO) to replace clearance-based operations in many parts of the airspace. New automated separation assurance functions are intended to help overcome the aforementioned limitations of controllers in manually maintaining safe separation between aircraft. The two primary new separation assurance concepts are airborne self-separation and ground-based automated separation assurance. Research is ongoing in both areas. NASA researchers, including the authors of this paper were part of prior human-in-the-loop assessments of mixed operations with airborne self-separation at more than two times today's traffic density. ${ }^{10}$ Various evolutionary concepts aimed at achieving incremental benefits over the next ten years, including the use of new decision support technologies, new data communication capabilities, new airborne spacing capabilities, and changes in the air traffic control team structure, have also been simulated with humans in the loop at various research institutions including NASA and MITRE CAASD. ${ }^{11-17}$ Initial laboratory demonstrations and closed loop automated evaluations of the enabling technologies for service-provider based automated separation assurance have now progressed the technology prototypes to start looking at the actual operations as envisioned under the far term concept of automated separation assurance. ${ }^{18,19,20}$

The research described in this paper, an initial part-task controller-in-the-loop simulation with ground-based separation assurance automation with double and triple traffic densities is therefore breaking new ground and should be viewed only as a first step towards understanding the complexities of human/automation interaction in the airspace system of 2025 and beyond.

Because this was the initial human-in-the-loop simulation of a new operating concept envisioned for 2025 there are many unknowns and problems that need to be dealt with. Technological unknowns include, but are not limited to aircraft equipage levels, ground-based workstations, data comm. infrastructure, trajectory prediction accuracies, trajectory tracking accuracies, conflict prediction accuracies, and conflict resolution performance. The roles and responsibilities of pilots and controllers and the automation are primary human factors research questions that can have a strong dependency on the technological environment. Clearly, this study can only address a very small subset 
of research questions and has to make informed assumptions about the many other open issues that need to be addressed by other research elements.

The focus of this study was controller/automation interaction in strategic trajectory-based separation assurance. The primary new assumption was that conflict detection was automated and the controllers had no responsibility to detect conflicts. They were however responsible to resolve conflicts using automation aids within a specified airspace region. One of the research questions was how much traffic in terms of density and complexity controllers could manage comfortably with different levels of automation support. Another important question was how efficient and acceptable the automation generated resolution advisories were to the operators and how automated resolution strategies compared to controller strategies. On a fundamental level the study was also intended to get more insight into what the appropriate role for the controller and the automation in the future system might be.

\section{Approach}

The approach to addressing the problem of controller/automation interaction in strategic trajectory-based separation assurance was to compare operations at different levels of automation to each other, to current day operations, as well as to a fully automated closed-loop system. Baseline data from current day operations could be gathered from previous experiments, but NextGen operations with trajectory-based automated separation assurance had to be newly simulated. For the initial ground-side study it was decided to simulate human/automation interactions only for the relevant aspects of this initial study and to automate all flight deck operations with reasonable assumptions about flight crew response times and aircraft tracking accuracies. Flight deck aspects will initially be addressed separately.

\section{A. Study Design and Independent Variables}

This study design can be represented as a multi-part study that varies the level of automation over the traffic density (Figure 1).

$\begin{array}{llll}\text { Traffic Density (number of aircraft per sector) } & 1 \times(15) & 2 x(30) & 3 \times(60) \\ \text { Productivity (number of aircraft per controller) } & 2 x(30) & 4 x(60) & 6 x(90)\end{array}$

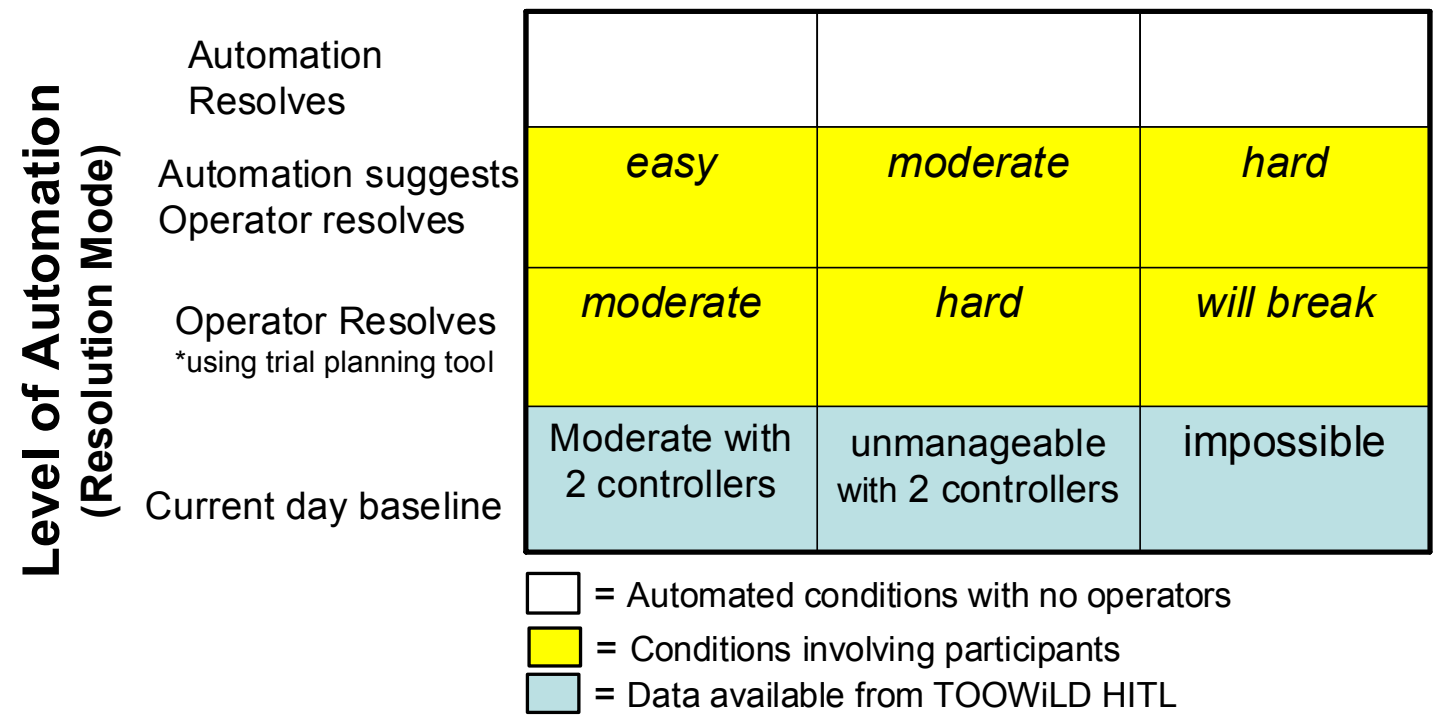

Figure 1. Ground Side Study Design and initial hypotheses about the task difficulty

\section{B. Level of automation:}

The term level of automation is used here as a simplified term for the human/automation interaction mode or the operating mode. The following levels of automation were chosen, because they were considered important distinct steps in the continuum of possible human/automation interaction modes: 
Automation resolves - conflict detection and resolution is automated and operators are not responsible for conflict detection and resolution. All conflicts are resolved sequentially at a predefined time to conflict (here 8 minutes). Resolution trajectories are automatically data linked to the aircraft. The only operator task is to ensure the system is running.

Automation suggests operator resolves - conflict detection is automated and operators are not responsible for conflict detection. The conflicts are depicted in order of time to conflict, the operator decides, when to resolve which conflict, the operator can request a conflict free trajectory from the automation, and modify it using a graphical trajectory (trial) planning function. The operator decides whether to send the resolution trajectory to the aircraft or cancel the modification.

Operator resolves using trial planning tool - conflict detection is automated and operators are not responsible for conflict detection. The conflicts are depicted in order of time to conflict, the operator decides, when to resolve which conflict, the operator generates the modification using a graphical trajectory (trial) planning function. The operator decides whether to send the resolution trajectory to the aircraft or cancel the modification.

Current day baseline - Operators are responsible for conflict detection and resolution just like today.

\section{Traffic Density}

The traffic densities were selected to excite the differences between the different levels of automation and represent the full spectrum of densities between today and the maximum density currently envisioned for NextGen. Based on related research ${ }^{17,20}$ it was assumed that $1 \mathrm{x}$ density could easily be handled by the operators in the parttask trajectory-based separation assurance environment and one operator should at least handle double the number of aircraft at the same density. Therefore, it was decided to use a combination of two sectors as test airspace. Two controllers worked these sectors in the current day baseline, while one controller worked the sector in the experimental conditions, doubling the aircraft count for all experimental conditions.

$1 x$ - This density represents typical current day high traffic density for the airspace in question. This density was run in the TOOWilD airspace and considered adequate by the air traffic controllers. 1x during the TOOWILD study resulted in the traffic count depicted in figure 2 with an average of approximately 15 aircraft per sector. This results in an average instantaneous aircraft count of 30 to be managed by one controller during the experimental runs.
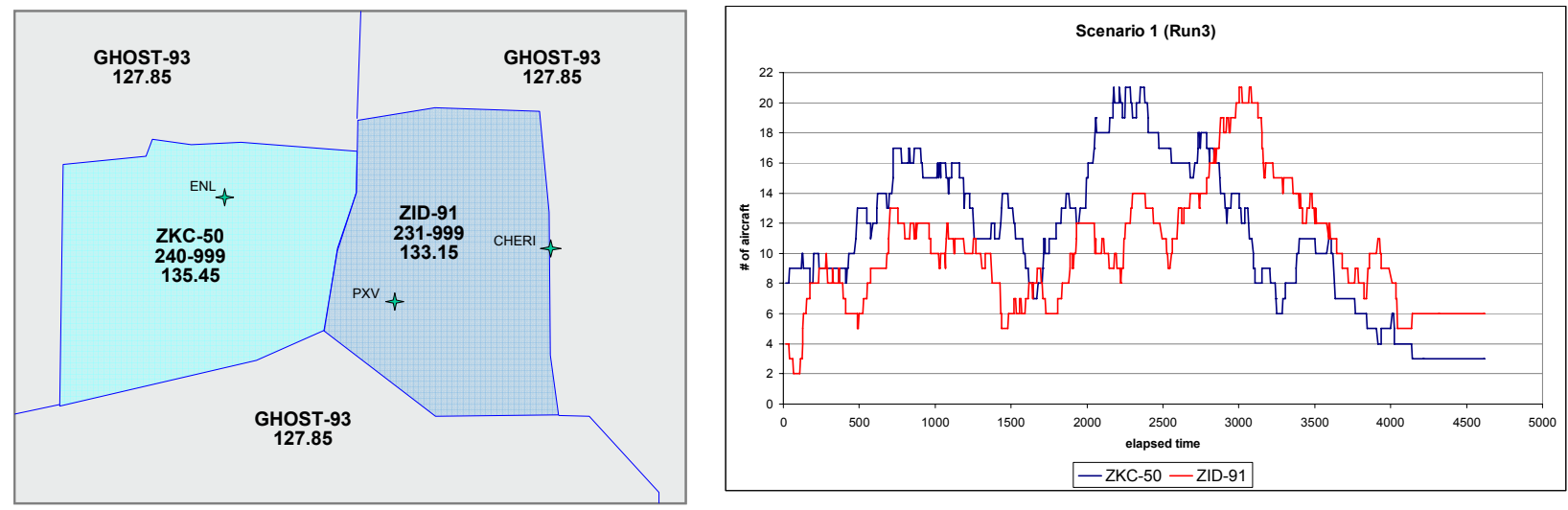

Figure 2. Test airspace and $1 x$ traffic count from TOOWiLD study in the AOL used as baseline ${ }^{7}$

$2 x$ - The density was doubled by inserting aircraft into the scenario with the same flight plans as for the $1 \mathrm{x}$ case at different starting locations and altitudes. It therefore maintained the same basic fixed route structure and traffic bottlenecks as the $1 \mathrm{x}$ case. Participant controllers were responsible for continuously managing an average of 60 aircraft during the runs.

$3 \mathrm{x}$-This density increase required to also insert aircraft with new flight plans and create more distributed traffic patterns than the $2 \mathrm{x}$ case. Traffic bottlenecks at the fixed route structure were saturated and additional aircraft had to be routed differently. The average instantaneous aircraft count was 90 per operator.

\section{Traffic complexity / conflict count}

As mentioned above the $1 \mathrm{x}, 2 \mathrm{x}$ and $3 \mathrm{x}$ scenarios were designed from current day traffic patterns. The traffic flows represent the complexity of the current day fixed route structure with significant bottlenecks. The part-task 
environment was focused on conflict resolution. The frequency of conflicts is summarized in Table 1 as an initial descriptor of traffic complexity for the different densities. Ongoing analysis using the study data for dynamic airspace capacity (DAC) applications is assessing other parameters to describe complexity in this environment ${ }^{24}$. The conflict counts in table 1 represent separation violations that were designed to occur within a 30 minute experimental run for the different traffic densities, if none of the trajectories were modified.

Table 1. Scenario characteristics

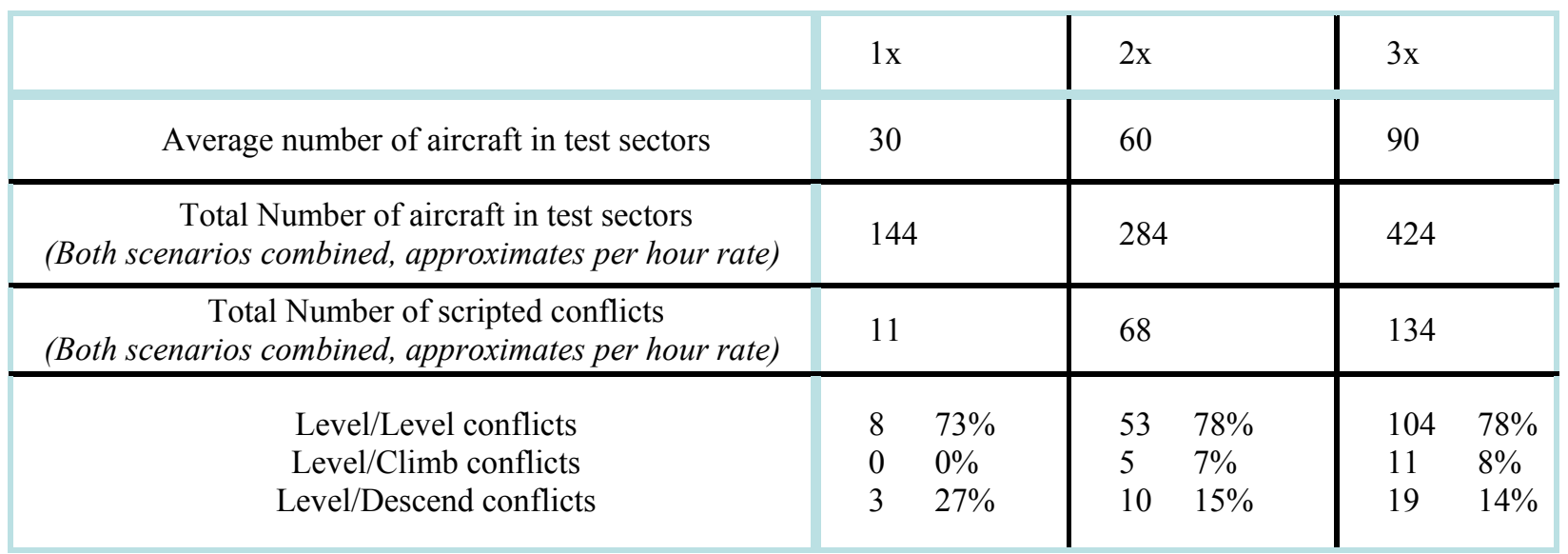

\section{Method}

The general method for the investigation is a combination of human-in-the-loop experiments and automation analyses. The experiments were conducted in the Airspace Operations Laboratory (AOL) ${ }^{8}$ at NASA's Ames Research Center. The following sections describe the simulation environment and the operator stations.

\section{A. Simulation Environment}

The experiments were conducted in the Airspace Operations Laboratory $(\mathrm{AOL})^{8}$ at NASA's Ames Research Center. Research in the AOL focuses on examining air traffic operations in rich air/ground environments that can include multiple oceanic, enroute, and terminal airspace sectors. The AOL has been designed for studying air traffic operations in the current day air traffic environment, potential NextGen operations, as well as the transitional stages in-between. The Multi-Aircraft Control System (MACS) ${ }^{22,23}$ is the AOL's software for rapid prototyping and controller- and pilot-in-the-loop simulations used to evaluate air/ground interactions in the National Airspace System (NAS). Over the past years powerful tools to support trajectory-based operations have been integrated into accurate emulations of flight deck and controller workstations within MACS. ${ }^{23}$

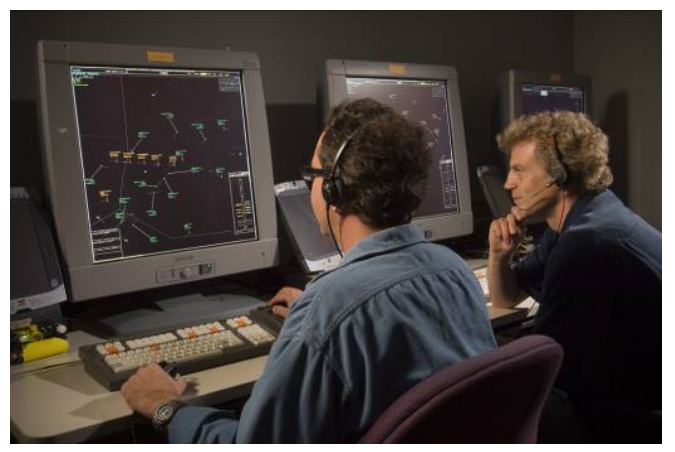

Figure 3. Air Traffic Control positions in the Airspace Operations Lab with MACS DSR display emulation

For this part-task study the conflict resolution algorithm that was developed as part of the research on the Advanced Airspace Concept (AAC) ${ }^{18}$ was integrated into MACS. This algorithm had been prototyped in JAVA. After implementing the appropriate adapters and factories, the original conflict resolution software could be used without modification inside MACS. More details on the conflict resolution algorithm can be found in Erzberger's publications ${ }^{18}$. A subsequent section describes the MACS/conflict resolution integration in more detail. To aid in the evaluation the analysis software used during the AAC development was also ported into MACS. This web-based service (see also Figures 7 and 8) enables highly efficient collaboration of researchers in assessing the performance of the software as well as the detailed analysis of each conflict resolution step, manual or automated. 


\section{B. Simulated NextGen Airspace Environment}

The following assumptions were made with regard to the simulated air traffic environment. All aircraft were equipped with a Flight Management System and a data comm. capability that enables uplink and processing of routes and altitudes (similar to FANS 1/A). Precise position and speed information was available for all aircraft that could be achieved with ADS-B. The lateral navigation performance of the aircraft was assumed to be RNP 1 or better. The ground system maintained 4D trajectories for all aircraft, based on filed flight plans and planned climb, cruise and descent speeds that could be submitted pre-flight by the airline of from the flight deck. Trajectory changes are implemented by the controllers using trajectory planning tools that create and distribute the appropriate trajectory amendments throughout the ground system.

For this simulation a new set of flight rules was invented, labeled "Trajectory-based Flight Rules" or "TFR". This idea was adapted from the introduction of "AFR" or "Autonomous Flight Rules" in earlier DAG-TM work ${ }^{10}$. The responsibility for detecting conflicts involving TFR aircraft resides with the ground automation (and not with the flight deck as was the case for "AFR" aircraft). "TFR" Aircraft were cleared to fly along their trajectory unless instructed otherwise by the controllers. Aircraft are therefore assumed to change altitudes at the top of descent or start of climb points programmed and predicted in their FMS trajectories.

\section{Controller workstation}

The display modifications to go along with the added automation and the new allocation in roles and responsibilities between controllers and automation were accomplished through changes to MACS' configuration
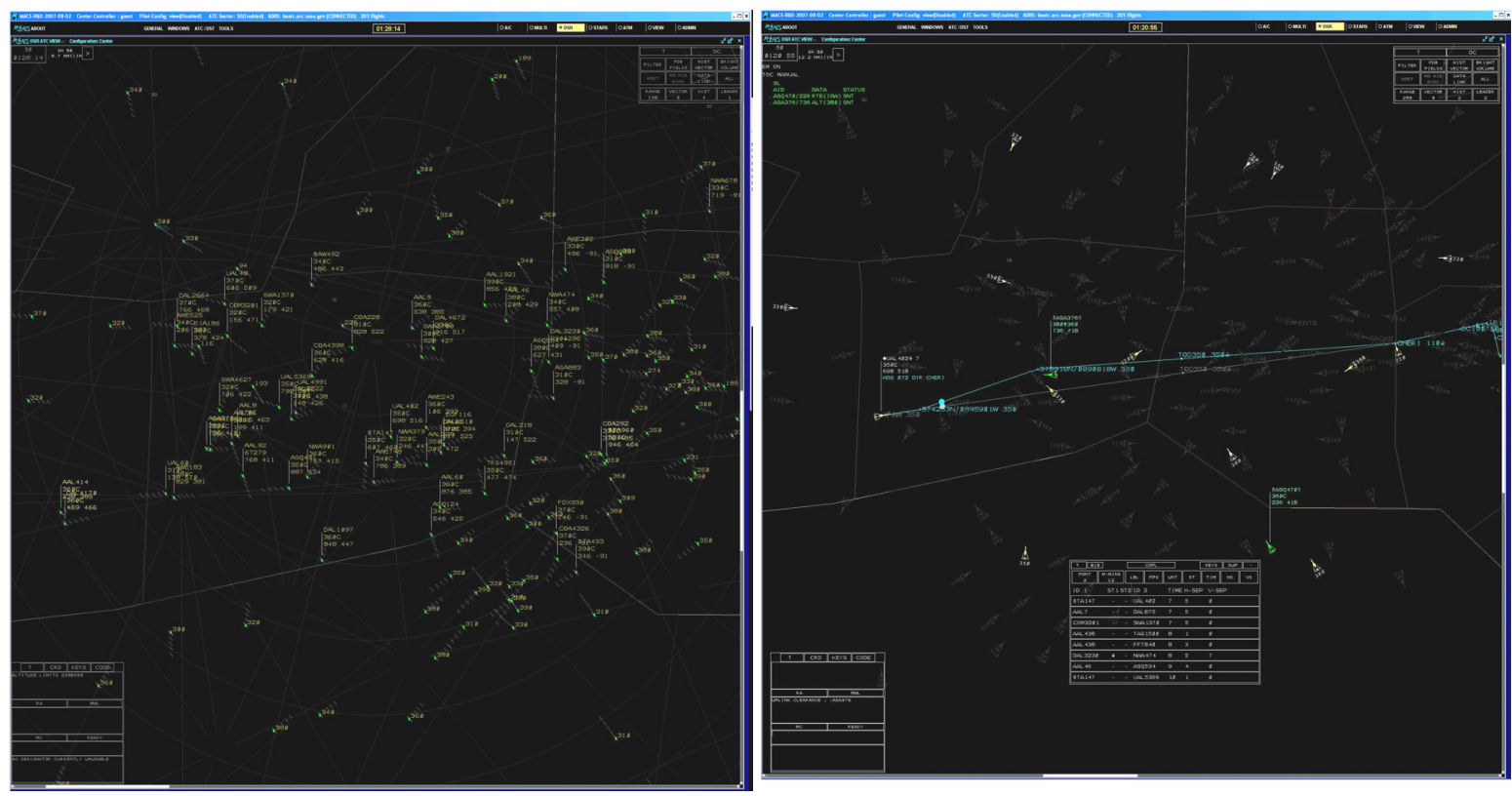

Figure 4. Display design for AAC part-task study. On the left is a current day DSR display as it would look with 3x traffic in a single sector. A prototype controller display with $3 x$ traffic designed for working conflict resolutions in two combined sectors is shown on the right.

options. Most notably to the operators were the changes to the look and feel of the DSR screen. The MACS framework was used to configure a controller display for future air traffic operations that would be very different from what they are today. In a current day DSR screen, the data block for each aircraft owned by a controller must be fully displayed while inside their sector or whenever the controller has track control. Once an aircraft is handed off and outside of their sector, the controller can then collapse, or minimize, the data block of that aircraft in order to reduce clutter and possible confusion. When increasing traffic two and three times from current day levels, the display would become so cluttered with each aircraft's data block that the individual working the sector would spent nearly the entire time trying to de-clutter their display. This would leave no time to deal with air traffic control tasks, such as separation assurance. The clutter would make it difficult to even identify any aircraft in conflict, severely constraining the participant's ability to conduct any reasonable job. 
As a result, changes were made to the DSR screen that support controllers managing separation assurance by creating conflict resolution trajectories under such high traffic volumes. These changes to the DSR look and feel were done with the configuration setup panels in MACS. The biggest change came from a set of rule-based behaviors assigned to the data blocks. Assignable rules were defined to display the data blocks according to their conflict status:

1) If no conflict is detected, display as a limited data block in dark grey

2) If a conflict is detected between 9 and 12 minutes out, display as a limited data block in white

3) If a conflict is detected between 5 and 8 minutes out, display as a limited data block in yellow

4) If a conflict is detected less than 5 minutes out, display as a limited data block in orange

With the aircraft in conflict highlighted, the controller could then easily access that aircraft's full data block by clicking on the aircraft symbol.

Incorporating the tool sets developed in previous AOL simulations, the full data blocks included a "portal" to access the trialplanning function. Integrated with a highly responsive conflict probe, the trial planner gave the controller participants the ability to manually create conflict-free routes for all aircraft. These trajectories were combined with datalink, allowing the controllers to send the new routes directly to the aircraft as described in ${ }^{11}$.

As a new feature controllers were able to use the conflict list, the data tag's portal or the data tag's altitude field to request an automation generated conflict resolution proposal with a preference for a lateral, or an altitude maneuver, respectively. This automatically generated resolution trajectory was loaded as a trial plan for review and uplink to the aircraft by the controller. Since it was presented as a trial plan, controllers could also modify the auto-resolution manually to "tweak" it. This interactive mode
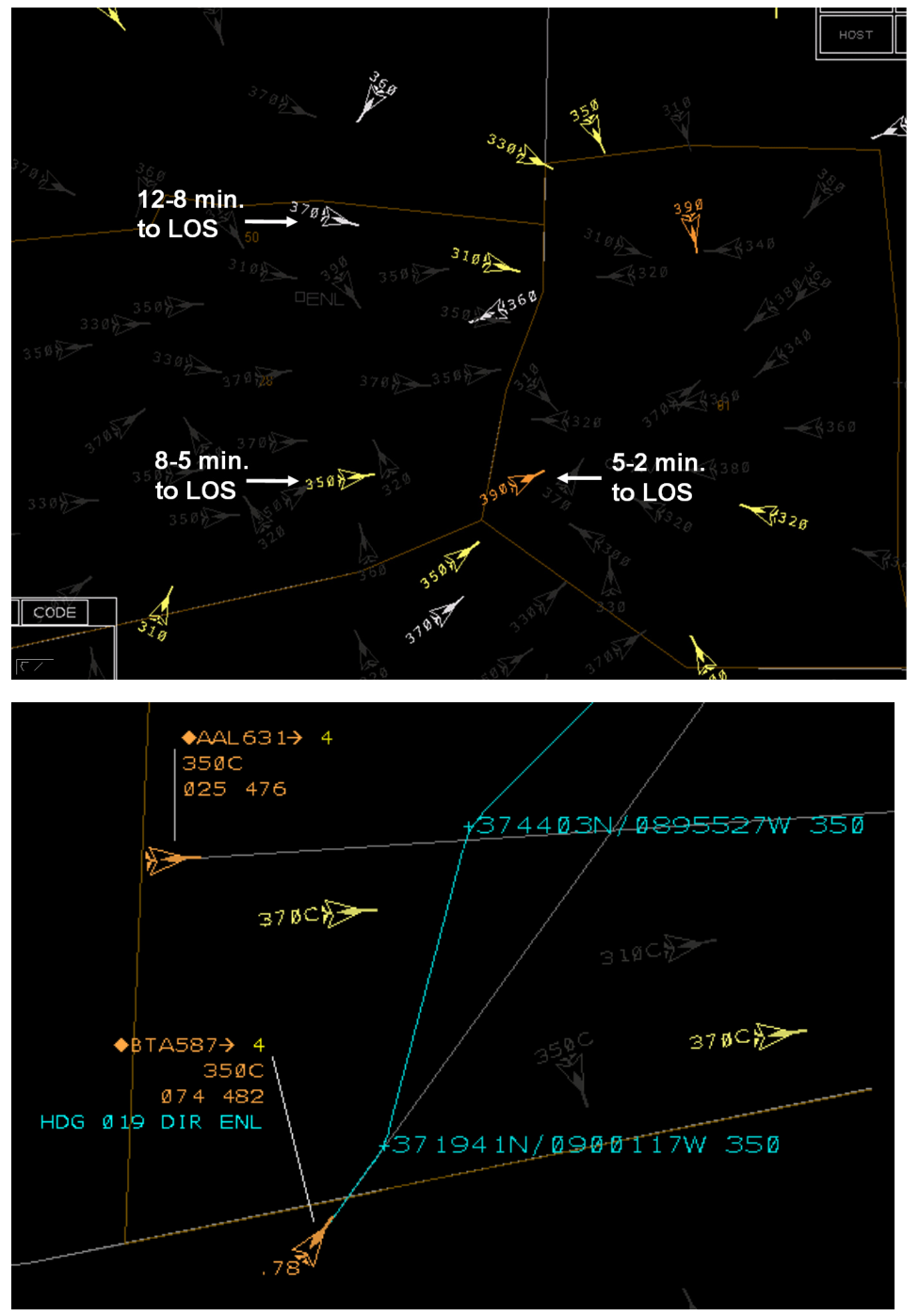

Figure 5. Prototype display with directional chevrons and color coding by time to LOS (top) and auto-resolution presented as trial plan (bottom) was seamlessly integrated into the general display philosophy and allowed for a straightforward human/automation interaction.

\section{Conflict detection}

The MACS conflict detection logic conducts a deterministic conflict search along the flight plan-based trajectories stored in the ground-based system as long as aircraft are in compliance with their trajectories. Once out of conformance, MACS generates flight state based trajectories for 5 minutes and uses those for conflict probing. A potential separation violation is flagged when level-flight aircraft are predicted to get closer than $5.5 \mathrm{NM}$ and 1000 feet of each other, and when transitioning aircraft are predicted to get closer than 5.5 NM and 1500 feet. The MACS trajectory engine uses aircraft performance models and real-time information to predict up to 12 different flight deck and ground-based trajectories for each aircraft. Atmospheric conditions, such as winds, can be varied between 
environment, ground-based forecast and flight deck forecast. Different surveillance models can also be selected to model additional uncertainties impacting the trajectory prediction errors in addition to flight technical and actual navigation performance errors. For this experiment it was decided not to introduce wind errors and use the best surveillance source available. Thus, primarily trajectory modeling and flight technical errors remained, making the conflict detection fairly reliable. However, it was particularly climbing aircraft causing late, false and missed alerts. The overall trajectory-based conflict detection rate in this configuration is approximately between $95 \%$ and $98 \%$ depending on the time to LOS.

In addition to the trajectory-based conflict detection a state-based conflict alert function is independently evaluating the traffic situation for near-term conflicts. This function is typically configured to look at 0 to 2 minutes to LOS and has practically no missed alerts, and few false alerts. During the experiment this function was only used for data collection purposes and not presented to the controllers. Controllers were not expected to resolve short-term conflicts

\section{E. Conflict Resolution}

Where appropriate, MACS can host and integrate externally developed prototypes. For the initial study discussed in this paper, the "auto-resolver" was integrated into MACS, developed by Heinz Erzberger and his team at NASA Ames Research Center. The "auto-resolver" is a trajectory-based conflict resolution algorithm that provides efficient flight path changes to solve medium term conflicts ${ }^{24}$

The software was directly integrated into MACS by accessing the original JAVA code through the given programming interfaces. This enables MACS to run the exact same software that is also integrated into the Airspace Concept Evaluation System ACES for fast-time simulation purposes ${ }^{19,25}$ and into the Center TRACON Automation System CTAS for analysis and testing under all the uncertainties of a live data-driven environment ${ }^{26}$.

The auto-resolver is integrated into its hosts, such as MACS, ACES, or CTAS, in an iterative manner. For the implementation used in the AOL, MACS is responsible for conflict detection and provides a conflict description to the auto-resolver. The auto-resolver uses its carefully designed logic and a selected prioritization scheme to determine viable solutions and evaluate each candidate trajectory change. Each candidate trajectory that passed an initial test is evaluated using MACS' trajectory generator and conflict detection logic. The potential resolution trajectory is checked against all other trajectories to determine whether any two aircraft will come within $7 \mathrm{~nm}$ of each other. If not, the trajectory is declared conflict free and stored as a successful solution. All successful solutions are compared to each other with regard to the additional flight time or magnitude of change that they impose on the individual flight. Finally the best solution is selected and presented to the controller or uplinked to the aircraft.

Controllers can manually request an auto-resolution any time after the conflict is detected or resolve the conflict manually with the trial planning tools. During the fully automated runs the system automatically generated resolutions within 8 minutes before the predicted los of separation (LOS). The auto-resolver was configured to look for lateral maneuvers first when there were more than 4 minutes to LOS and start the trajectory change 90 seconds into the future to give pilots and the system time to evaluate and implement the change. When a LOS was predicted to occur within 4 minutes, preference was given to altitude resolutions and the first trajectory change was expected to take place within 30 seconds. Controllers could also request the altitude preference when enacting individual conflict resolutions if so desired. Data generated during the conflict resolution cycles are stored in a MySQL data base that can be uploaded to a web-based server for detailed analysis and inspection of each iteration cycle. This feature is explained in the metrics section of this paper.

\section{F. System/Lab configuration}

Being an initial look at a completely new air traffic environment it was important to have enough participants interact with the same traffic scenarios and human/automation integration conditions. Therefore the lab communication architecture was modified to enable the parallel simulation of three decoupled scenarios in three clusters. Each cluster contained a simulation manager, a ghost ATC station, a supporting pseudo pilot station, a data collection station and the participant position. Figure 6 depicts the communication architecture. All support positions were almost entirely automated and required only minimal supervisory oversight to make sure the MACS stations were processing all received commands appropriately.

The same scenarios were started at the same start time on all three clusters and participants were presented with the same traffic problem and condition simultaneously. Therefore, in each two day experiment session, training and data collection for three participants could be conducted simultaneously creating a very efficient study environment. 


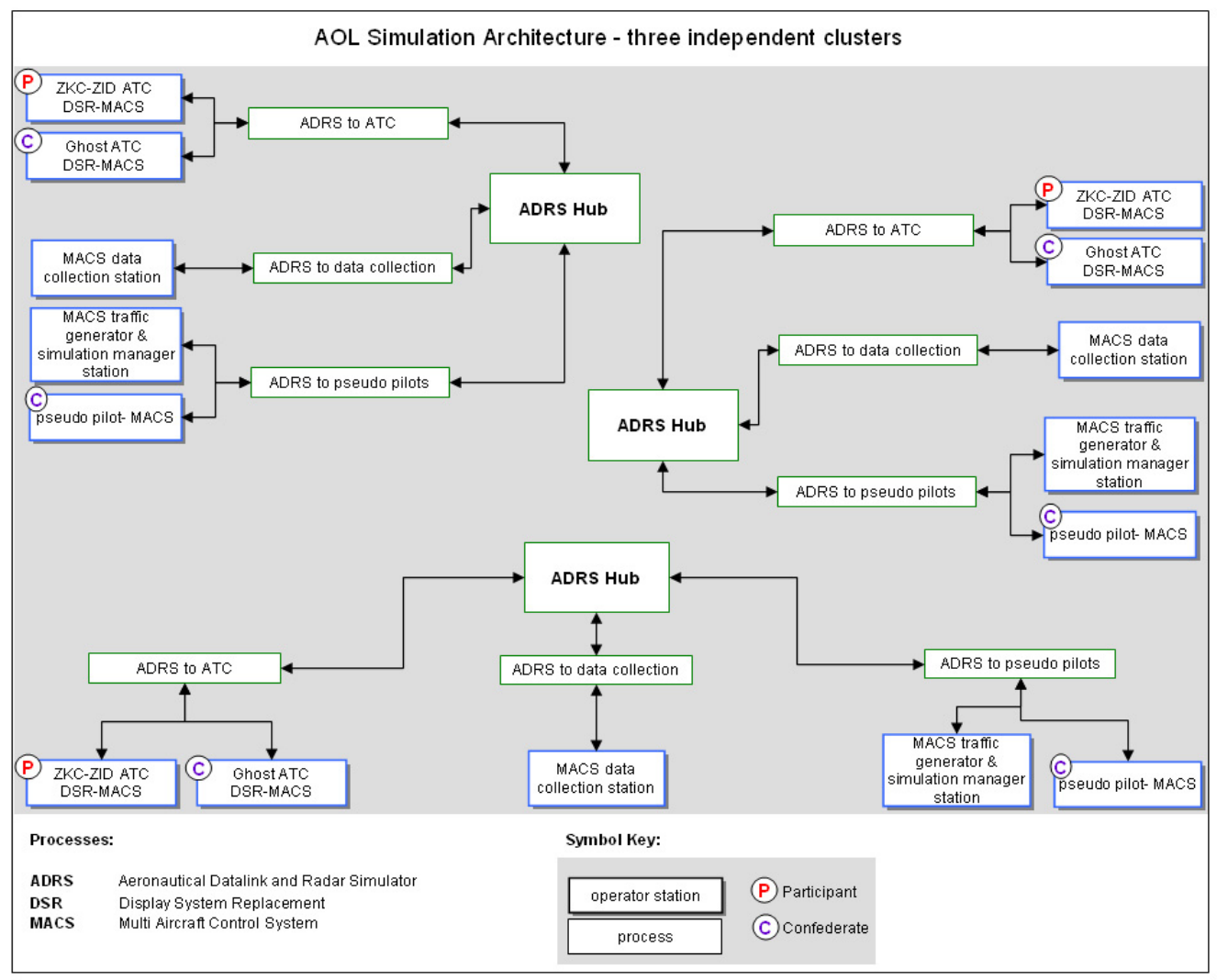

Figure 6. Communication infrastructure for part-task study on service provider-based automated separation assurance. Three independent clusters with automated MACS support stations enable concurrent data collection for three participants

\section{Data Collection}

This section first presents the organizational aspects consisting of the data collection activities, the participants and the daily schedule, and then the collected measures and metrics are reviewed. The study results are presented in the subsequent section.

\section{A. Organizational Aspects}

1. Data Collection Activities

The following data collection activities contributed to this study

- TOOWiLD study served as current day baseline (August 2006) ${ }^{7}$ :

An experiment on Trajectory Oriented Operations with Limited Delegation (TOOWiLD) in the AOL had controllers work similar traffic patterns in the same airspace under current day conditions. This study was run in August 2006 und used as the current day baseline to develop realistic scenarios at current day workload levels.

- Part-task study with controllers in the loop at different levels of automation (August 2007)

Assuming automated conflict detection human controllers provided trajectory-based separation assurance using

○ manual trial planning

- automated conflict resolution trajectories on request and manual trial planning

- Automation Analysis (August 2007)

The trajectory-based separation assurance automation was run for all experimental scenarios and conditions in a closed loop mode to assess the automation behavior in the part-task simulation environment without 
human intervention. This automation analysis was conducted immediately after the part-task study using the exact same software.

\section{Participants:}

Radar certified air traffic controllers participated in the experimental runs during the 2006 TOOWiLD simulation that provided the current day baseline data. For the experimental NextGen study described in this paper it was decided not to use active air traffic controllers to avoid the added complexities and cost of recruitment. This also properly accounted for the early development stage of the simulated operations. Therefore, two groups of participants were recruited, recently retired air traffic controllers (ATC) and aviation knowledgeable (AK) students. The two groups were selected to represent current generation air traffic controllers as well as operators that grew up with automation and could be the NextGen controller generation. At the onset of the study there were no specific expectations as to whether these two groups would turn out to behave differently or not.

\section{Daily Schedule for the part-task simulation}

The daily data collection schedule is shown below. Each participant conducted the same runs during two days of data collection.

Table 2: Data collection schedule for part-task simulation

\section{Day 1}

\begin{tabular}{|l|l|l|l|l|}
\hline $9: 00$ & Admin./Brief & & & \\
\hline $9: 30$ & Begin training & & & \\
\hline $12: 15$ & Lunch & & & \\
\hline 1:15 & Resume training & & & \\
\hline $2: 00$ & Data Collection: Run 1 & 1X & Manual & Blue \\
\hline $2: 50$ & Run 2 & 2X & Interactive & Blue \\
\hline $3: 40$ & Run 3 & 3X & Manual & Blue \\
\hline 4:30 & Run 4 & 1X & Interactive & Gold \\
\hline
\end{tabular}

Day 2

\begin{tabular}{|l|l|l|l|l|}
\hline 9:00 & Run 5 & 2X & Manual & Gold \\
\hline $10: 00$ & Run6 & $3 \mathrm{X}$ & Interactive & Gold \\
\hline 11:00 & Run 7 & $3 \mathrm{X}$ & Interactive & Blue \\
\hline $11: 30$ & Lunch & & & \\
\hline $12: 30$ & Run 8 & 2X & Manual & Blue \\
\hline $1: 20$ & Run 9 & $1 \mathrm{X}$ & Interactive & Blue \\
\hline $2: 10$ & Run 10 & $3 \mathrm{X}$ & Manual & Gold \\
\hline $3: 10$ & Run 11 & 2X & Interactive & Gold \\
\hline 4:00 & Run 12 & 1X & Manual & Gold \\
\hline 4:30 & $\begin{array}{l}\text { Debrief/Make-up runs } \\
\text { if needed }\end{array}$ & & & \\
\hline
\end{tabular}

\section{B. Measures and Metrics}

The measures and metrics covered three objectives of the simulation.

- Analysis of individual conflict resolutions

- Complexity measurements

- Primary study metrics

\section{Conflict resolution analysis}

In order to examine and analyze the individual conflict resolutions, an SQL based conflict resolution analysis software package developed for the advanced airspace concept was integrated into MACS. This package enables all conflict resolution related data to be uploaded into a SQL data base, which can then be queried by regular web browsers. This capability was available for automated conflict resolutions and was extended to manual resolutions. It provides experimenters and analysts a way of reviewing each conflict and resolution attempt in all details. Figures 7 and 8 below show an example from the data collection runs. Figure 7 depicts the overview page for a specific $3 \mathrm{x}$ 
run, listing summary information and all individual conflicts. Figure 8 shows the resolution that was selected for one specific conflict. This information was used to verify that the automated resolution algorithm was implemented adequately and to examine comparisons between manual and interactive solutions.

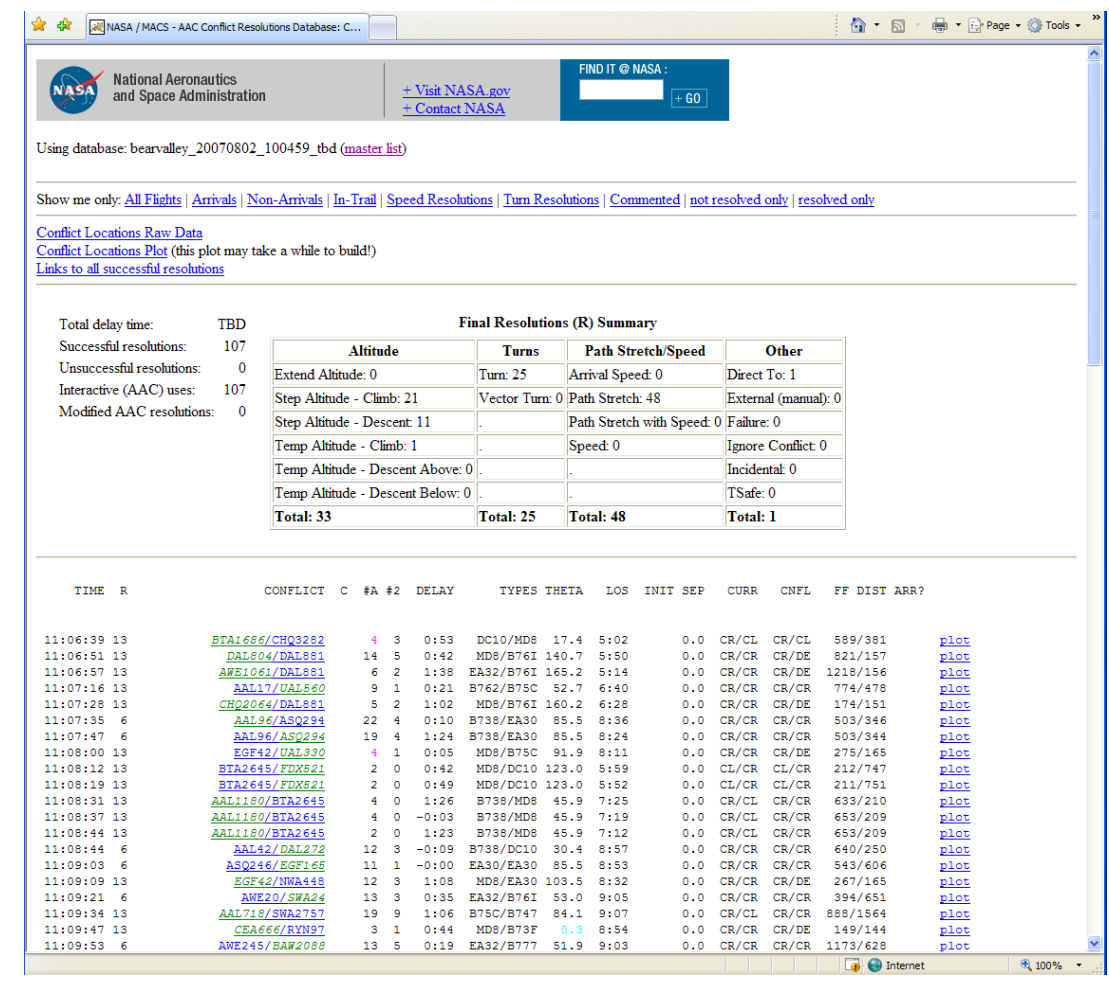

Figure 7. Conflict resolution summary for a $3 x$ run

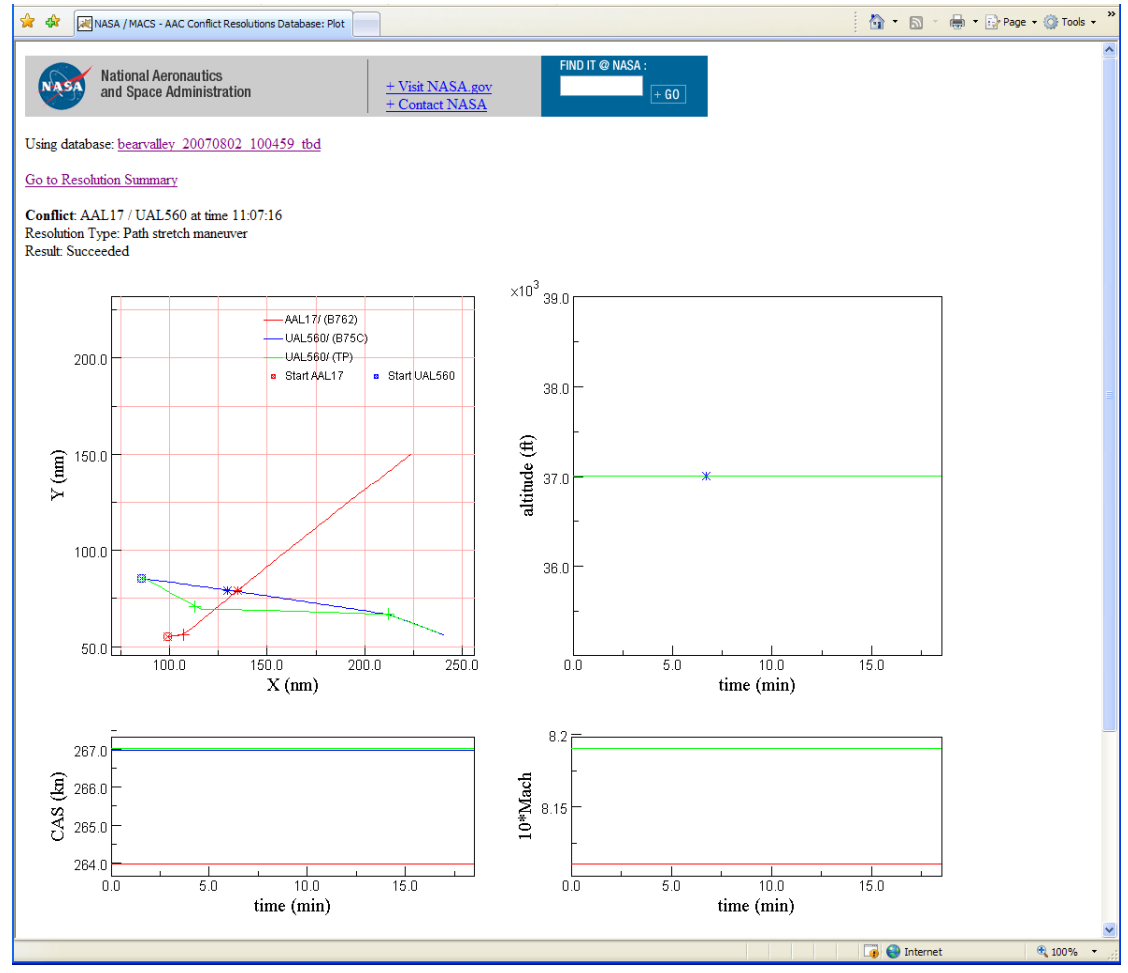

Figure 8. Example conflict that was resolved with a horizontal path stretch maneuver

American Institute of Aeronautics and Astronautics 


\section{Complexity measurements}

Specific complexity metrics were recorded and analyzed to understand the complexity factors that affect controller workload under higher levels of automation of conflict detection and resolution. The results of this research is reported by Kopardekar et al. (2008) ${ }^{24}$.

\section{Primary study metrics}

The following measures will be presented in the results section to compare and contrast the different controller/automation integration concepts:

- System performance and acceptability of individual conflict resolutions

- Number of requested/modified conflict resolutions

- Post-run questionnaire acceptability of resolution advisories

- Workload

- Real time ratings (Workload Assessment Keyboard)

- Strategy

- Safety

$\circ \quad$ Use of lateral vs. vertical maneuvers

- Number of separation violations

- Separation distances

- Efficiency
- Time added per trajectory change
- Altitude changes for conflict resolutions
$\circ$ Cumulative delay

These measures were recorded using the MACS built-in data collection system and post-run questionnaires and will be explained in detail in the next section.

\section{Results}

As a brief summary of the results it can be stated that in the simulated part-task setting the $2 \mathrm{x}$ density was very manageable and adequate for the interactive mode and was somewhat manageable with a manual trial planner. $3 \mathrm{x}$ density was somewhat manageable interactively, but would not pass the "spill your coffee" test. 3x density was unmanageable using the trial planning function alone.

\section{A. System performance and acceptability of individual conflict resolutions}

There were significant differences between the air traffic controller group and the student group in operating the interactive mode.

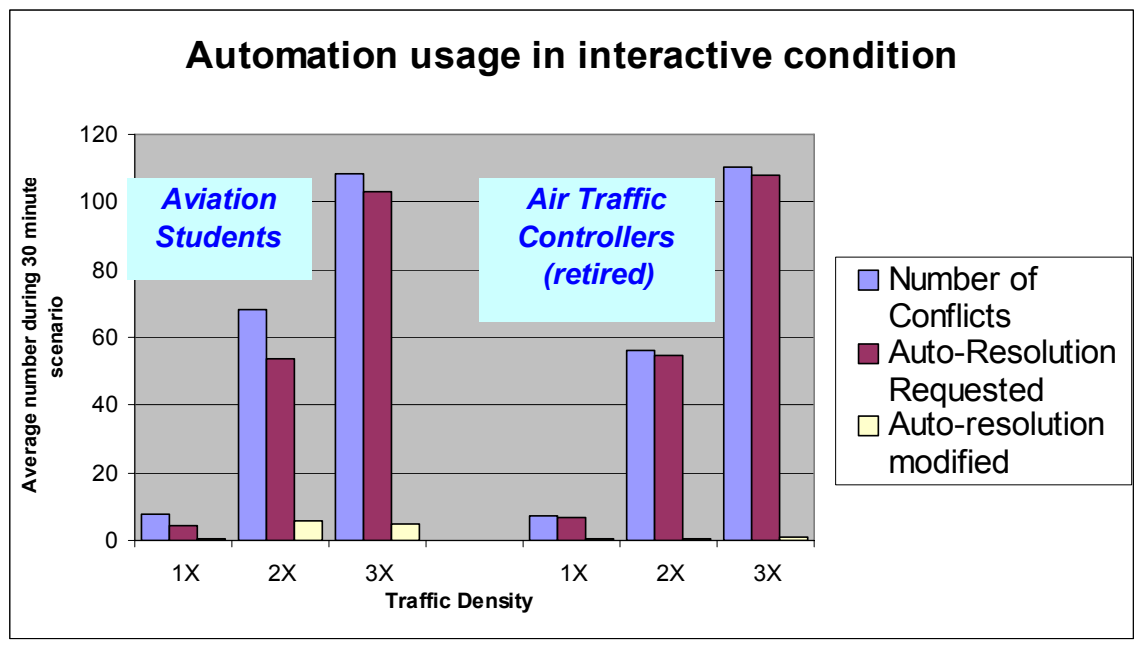

Figure 9. Automation usage in interactive condition 
The retired air traffic controllers consistently requested the automated resolution advisories in the vast majority of all conflicts with an average of $95 \%(1 x), 98 \%(2 x)$ and $98 \%(3 x)$ of the conflicts encountered. The controllers modified very few of the resolution advisories, and "tweaked" only approximately $4 \%(1 \mathrm{x}), 1 \%(2 \mathrm{x})$ and $1 \%(3 \mathrm{x})$ of all resolution advisories. The students showed a much more diverse behavior and requested the automation advisories on average only for $56 \%(1 \mathrm{x}), 80 \%(2 \mathrm{x})$ and for $95 \%(3 \mathrm{x})$ of the conflicts. They also modified more resolutions with averages of $17 \%(1 \mathrm{x}), 11 \%(2 \mathrm{x})$ and $5 \%(3 \mathrm{x})$. Figure 9 depicts these results.

In post-run questionnaires participants also rated the acceptability of the suggested conflict resolutions by answering the question" "How acceptable do you feel the suggested conflict resolutions from the automation were?" on a scale of $1=$ completely unacceptable to $7=$ completely acceptable. The results are depicted in Figure 10 below:

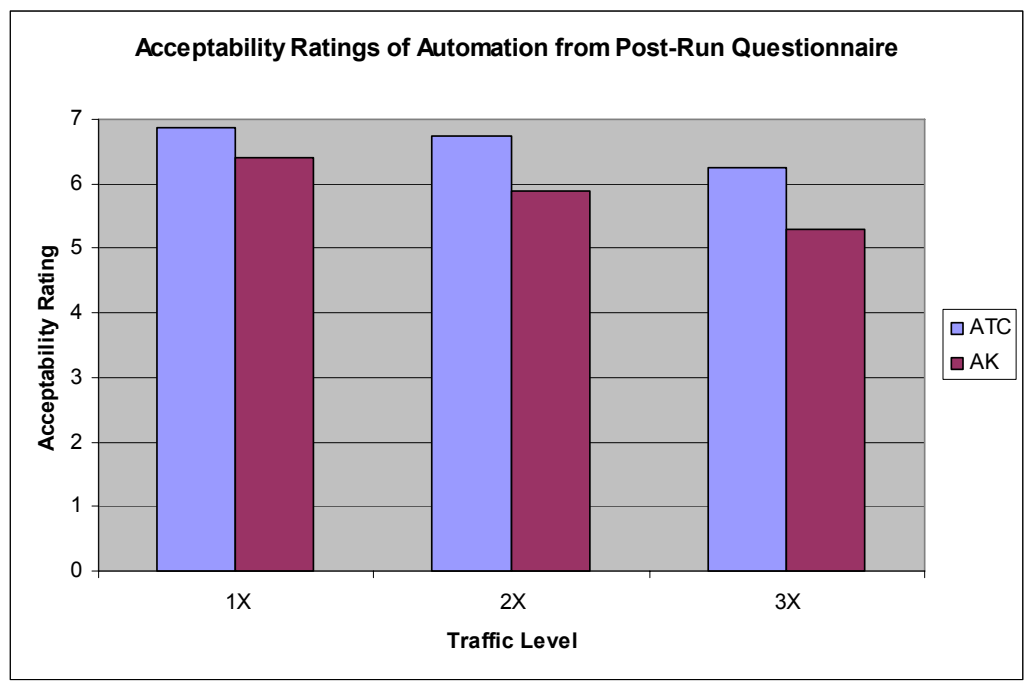

Figure 10. Acceptability ratings of individual conflict resolutions

The results indicate that the resolutions were generally very acceptable with a slight degradation as the traffic density increases. Also the retired air traffic controllers (ATC) found the automated resolutions more acceptable than the aviation knowledgeable (AK) students.

\section{B. Workload}

Analysis of the controllers' workload ratings on a scale of 1 to 7 taken during and after the runs suggest that peak workload during the $1 \mathrm{x}$ case with two sectors was very low $(\sim 1)$. The $2 \mathrm{x}$ manual condition was significantly higher than the $2 \mathrm{x}$ interactive and the $3 \mathrm{x}$ manual was at the maximum (7). The $3 \mathrm{x}$ interactive ratings were high (4-6) but consistently less than the manual condition. With conflict detection being automated, the air traffic controller workload related to conflict resolution appears to correlate with the task load involved in the mechanical process of planning a resolution. The monitoring workload and routine task pattern required to achieve the necessary situation
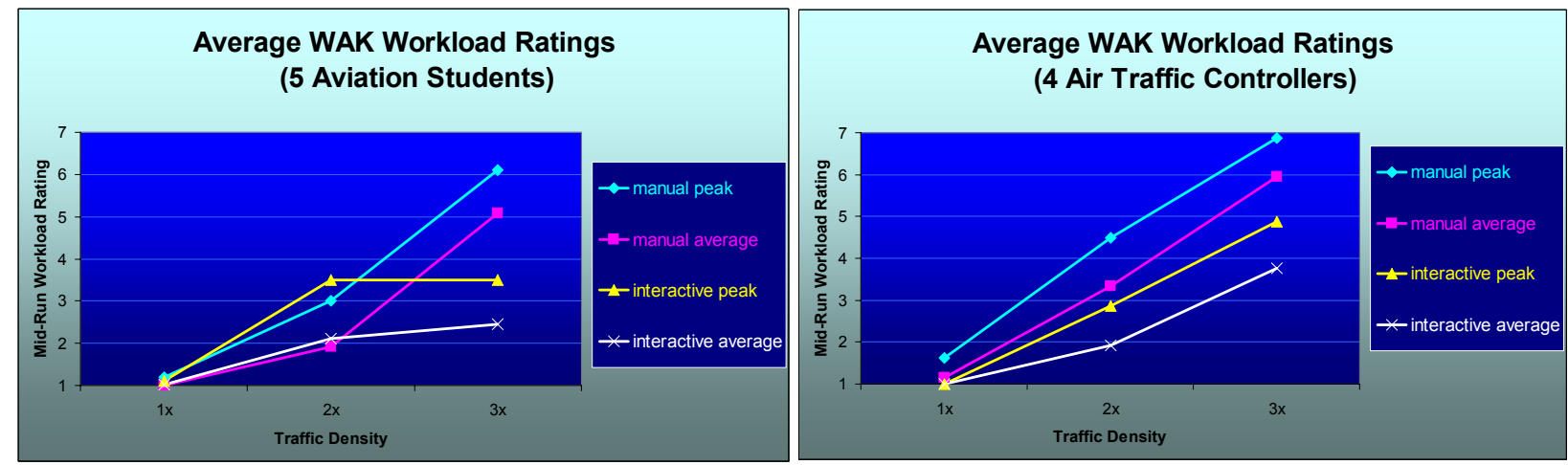

Figure 11. Workload ratings of aviation students and air traffic controllers

14

American Institute of Aeronautics and Astronautics 
awareness to work traffic in the current day environment has disappeared with automating the conflict detection process. This eliminates controller workload as the primary bottleneck in increasing sector capacity. Figure 11 shows the workload averages and peaks by participant group, operating mode and traffic density.

\section{Strategy Maneuver Selection}

In order to resolve conflicts participants could use vertical and lateral flight path changes and express preferences when requesting resolution advisories from the automation. The automation used a scheme, in which lateral maneuvers were preferred to vertical maneuvers until the delay imposed was too excessive. Figure 12 compares the maneuver selection of the air traffic controllers in the manual and semi-automatic (interactive) mode to the fully automated maneuver selection. The results show that in the manual mode, there was a similar preference for lateral maneuvers as with the auto-resolver, but that there was a shift to preferring vertical maneuvers at the $3 \mathrm{X}$ level.

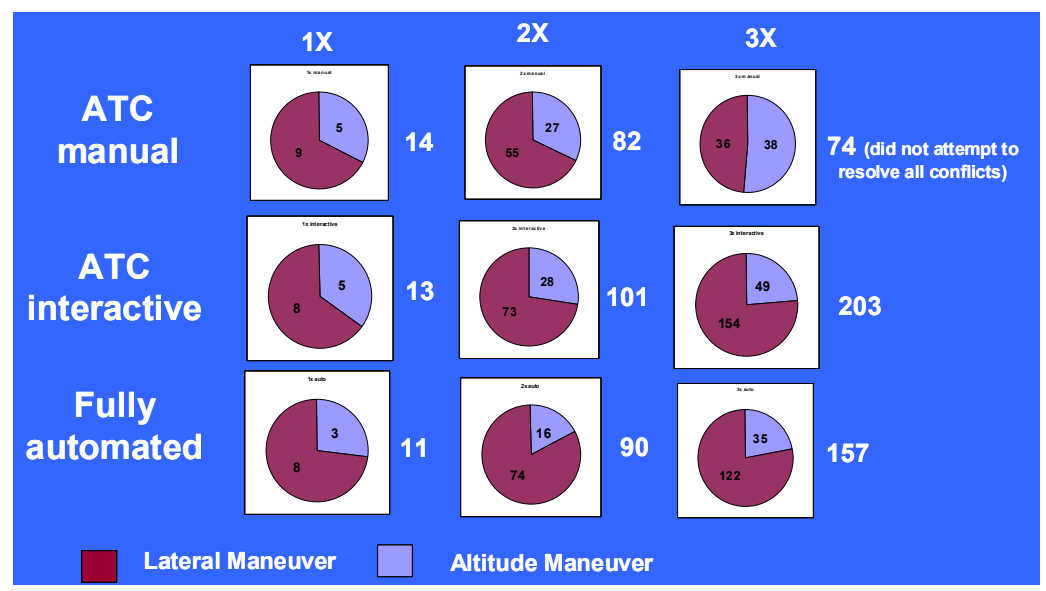

Figure 12. Maneuver selection of air traffic controllers and automation by operating mode and traffic density

The results for the interactive mode were similar to those for the fully automated mode, with one exception: In the interactive mode a larger number of resolutions was implemented than in the automated mode. This seems to indicate that the automated mode of operation is somewhat more effective in working the traffic problem than the interactive mode. Since the conflict resolution function is the same in both cases the primary difference likely resides with the timing of the conflict resolutions. The operators usually resolved conflicts as soon as they were detected, which was usually 12 minutes before LOS, whereas the automation did not resolve conflicts earlier than 8 minutes to LOS. Some of the conflicts were falsely detected by 12 minutes to LOS and the operators created a new trajectory and send it to the aircraft. By 8 minutes the conflict had already gone away and it never needed to be resolved by the automation.

Additionally new trajectories were generated to be conflict free for 15 minutes. In the interactive mode conflicts were detected and resolved at 12 minutes to LOS, and the new trajectory was conflict-free for 15 minutes. So a new conflict might be detected 3 minutes later. Theoretically a new conflict could be flagged every 3 minutes for each aircraft. In the fully automated mode all conflicts were resolved with 8 minutes to LOS, and the new trajectory was also conflict-free for 15 minutes. So a new conflict should not be detected before 7 minutes later. So, in this case a new conflict could be flagged every 7 minutes for the each aircraft. This would reduce the overall conflict count, but may require more drastic trajectory changes with less time to go to LOS.

These effects and the most effective combination of detection timing, resolution timing and conflict free path generation have to be further examined. The best settings will also depend on the prediction accuracy of the trajectories for the aircraft involved. For example conflicts between level flights can be detected and resolved much earlier than when transitioning aircraft are involved. Particularly climbing aircraft lead to much higher prediction uncertainties than level flights ${ }^{26}$.

\section{Safety}

Understand the safety implications of introducing individual components of the automated separation assurance functions are a critical step towards designing a safe system. In this first simulation a very good, but imperfect trajectory-based conflict detection function was used and no attempt was made to resolve near-term conflicts. The 
goal was to gain an initial idea on how often aircraft would get very close to each other if there was only a trajectory-based system and no safety net in place. While the imperfections of the trajectory-based system are realistic under real uncertainties, no-one would propose a system without a safety net. In fact, the tactical safety layer has always been part of the concept of automated ground-based separation assurance. The safety net was initially investigated in later studies. Nevertheless, it was important to determine when and how a trajectory-based system will be able to leave a solvable problem for the tactical safety layer. The analysis presented here is two-fold: separation violations and separation distances. The analysis of separation violations is summarized in Figure 13, which shows the average number of separation violations per scenario.

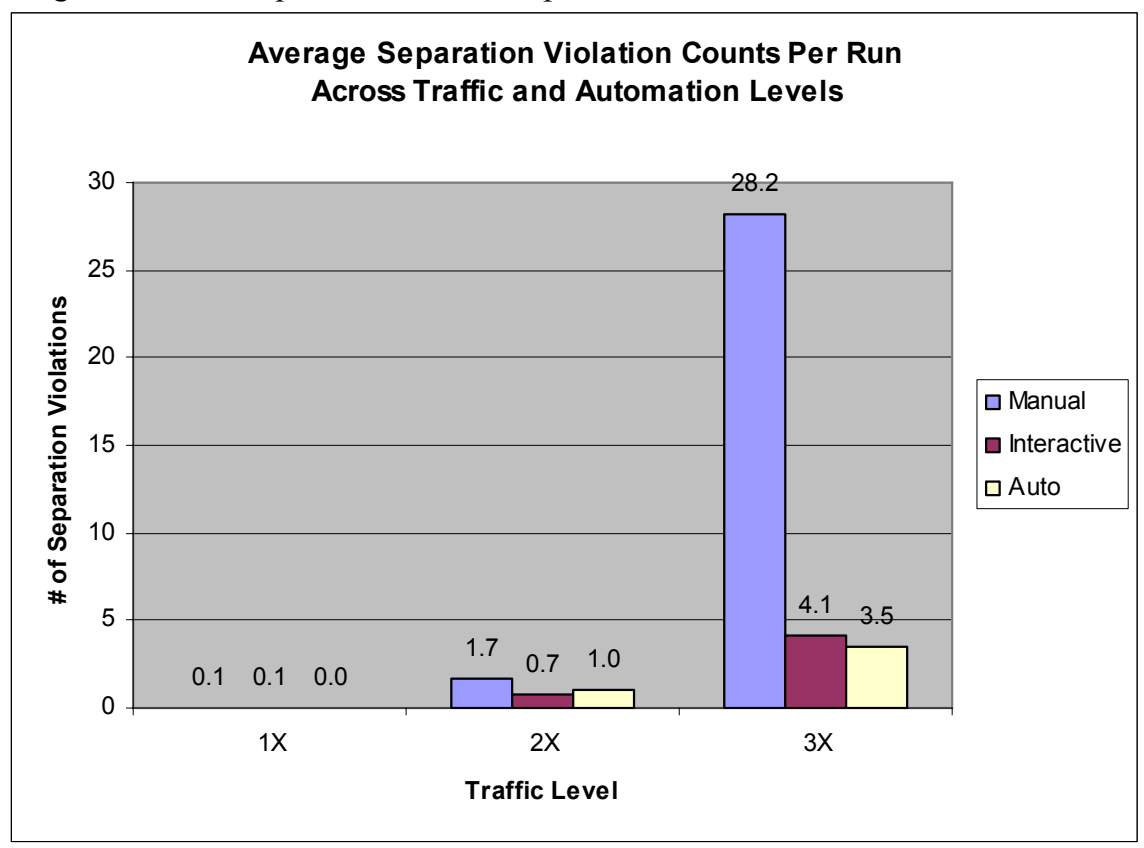

Figure 13. Separation violations per run by operating mode and traffic density

The conflict resolution function used in this study was intended to detect and resolve medium-term conflicts (3 to 12 minutes to loss of separation) with trajectory changes. Because of trajectory prediction uncertainties resulting from unknown environmental conditions, flight technical errors, improper trajectory modeling or non-compliance not all potential separation violations were detected early enough to be resolved by medium term trajectory changes. Therefore, it was expected that short-term conflicts would occur and that they would have to be resolved using the tactical safety assurance function. Additionally it was expected that managing the $3 \mathrm{x}$ density with manual trial planning tools is impossible and therefore would lead to many separation violations. Analysis of the separation violations during the test runs as depicted in Figure 13 confirms both those assumptions. It can be concluded that manual trial planning is an inappropriate operating mode in $3 x$ traffic. The separation violations in the interactive and the automated modes were the result of late conflict detections. Conflicts detected with less than three minutes to LOS were not intended to be resolved by the trajectory-based separation assurance function. Even though the number of such occurrences may be excessive, their existence confirms the need for the tactical safety layer which was a primary subject of the research conducted in summer $2008^{28}$.

In addition to simply counting separation violations, the separation distances were also analyzed. Figure 14 shows the results for the different levels of automation and traffic densities. Each graph indicates how many aircraft came within $5 \mathrm{~nm}$ and $1000 \mathrm{ft}$ of each other, which causes a separation violation and how many aircraft came within 5-10 $\mathrm{nm}$ and $1000 \mathrm{ft}$ over the course of an experimental run. The x-axis of each graph depicts the run time consisting of 30 minutes active conflict detection and resolution and 12 minutes of open loop simulation. The extra 12 minutes were added to complete the data collection and make sure the conflicts were actually resolved when the operators/automation had finished their work after 30 minutes. The results indicate once more how it was impossible to separate aircraft at $3 \mathrm{x}$ in the manual mode. On a different note, the operators spread the aircraft out further in the interactive mode than what a fully automated system does. Operators solved conflicts somewhat more conservative with extra buffers than the automation. This may increase the safety buffer, but at the same time reduce the 
achievable flow rate/traffic density. The primary factor impacting separation distances is obviously the traffic density as many more aircraft are getting close to each other when the density increases.
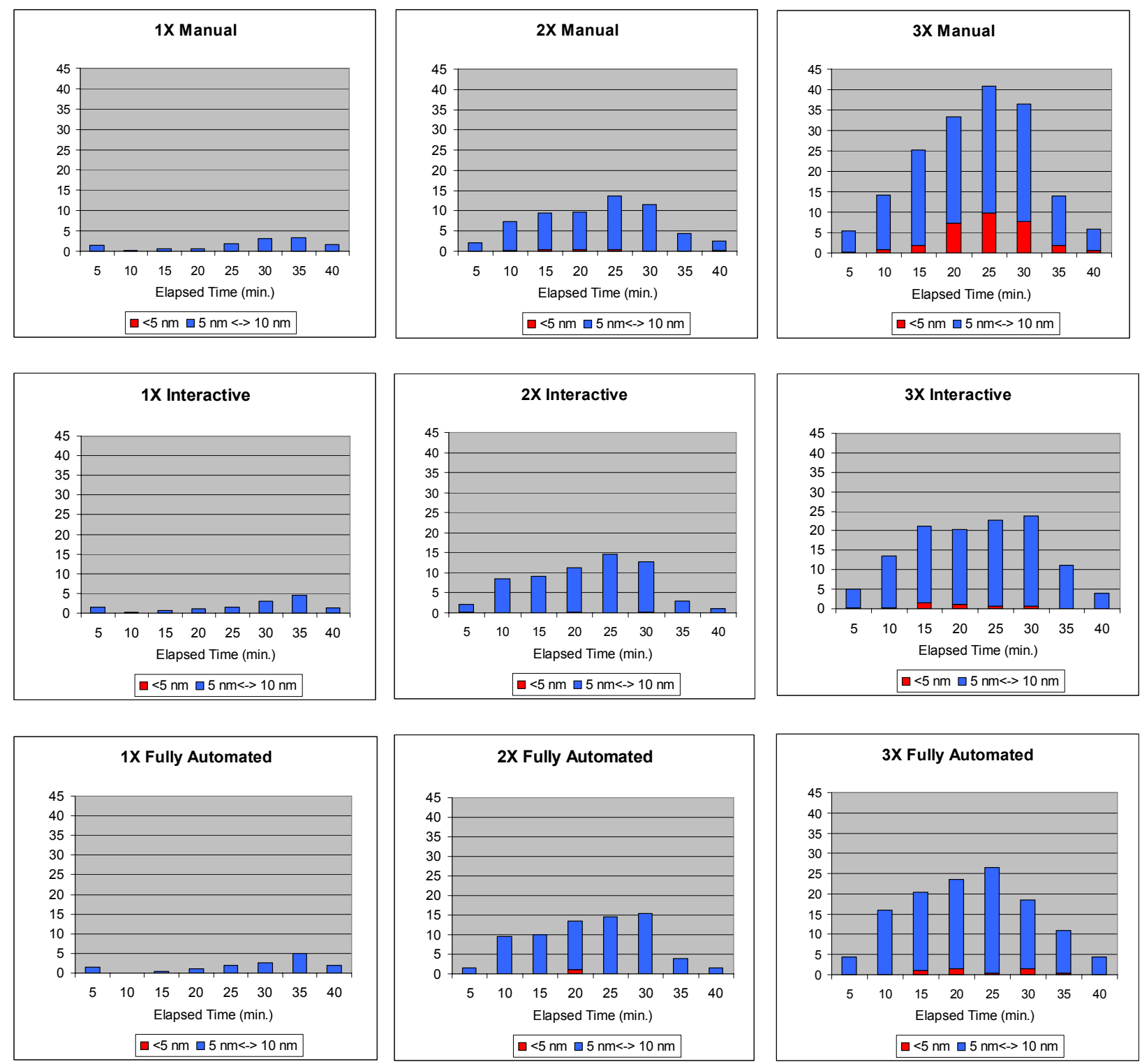

Figure 14. Separation distances by level of automation and traffic density

The comparison of the interactive and the automated mode in Figures 13 and 14 show how different control strategies can impact the separation distances without much impact on the number of separation violations.

\section{E. Efficiency}

As a measure of efficiency the time and delay added to the original trajectories was analyzed for the different conditions and participant groups. This section first discusses lateral delay and altitude difference by participant group and then presents average and cumulative numbers by level of automation only.

Figure 15 shows the average delay in seconds that was added by creating lateral conflict resolution trajectories. In the $1 \mathrm{x}$ and $2 \mathrm{x}$ cases some participants were able to create more efficient routings than the automation at the cost of additional workload (see above). At $3 x$ the participants achieved the same efficiency in the interactive mode as the automation. The solutions generated in the manual mode imposed significantly more delay than the automated solutions in $3 \mathrm{x}$. 


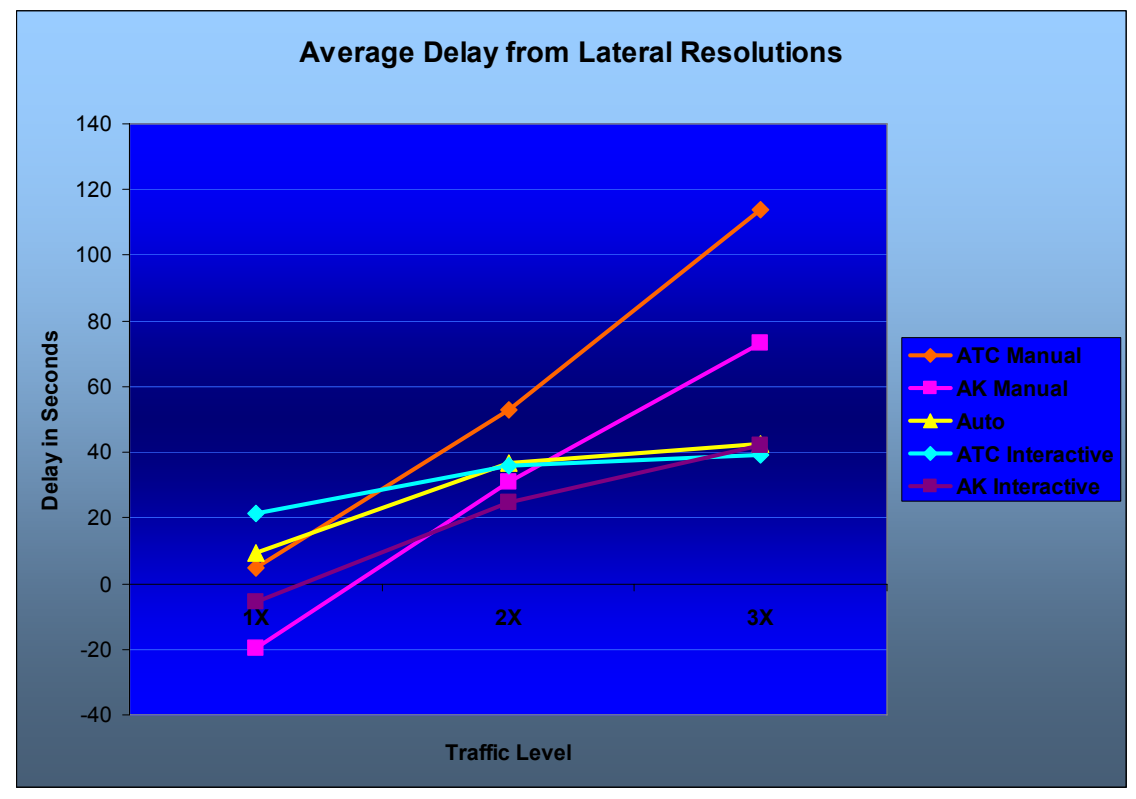

Figure 15. Efficiency of lateral resolutions measured as average flight delay resulting from each trajectory change

Figure 16 depicts the average absolute altitude difference per vertical trajectory change. The Air Traffic Controllers typically assigned bigger altitude changes in the manual mode, applying some of their current day techniques of descending arrivals early and keeping departures initially at lower altitudes. In the $3 \mathrm{x}$ condition controllers, and students assigned slightly smaller changes than the automation.

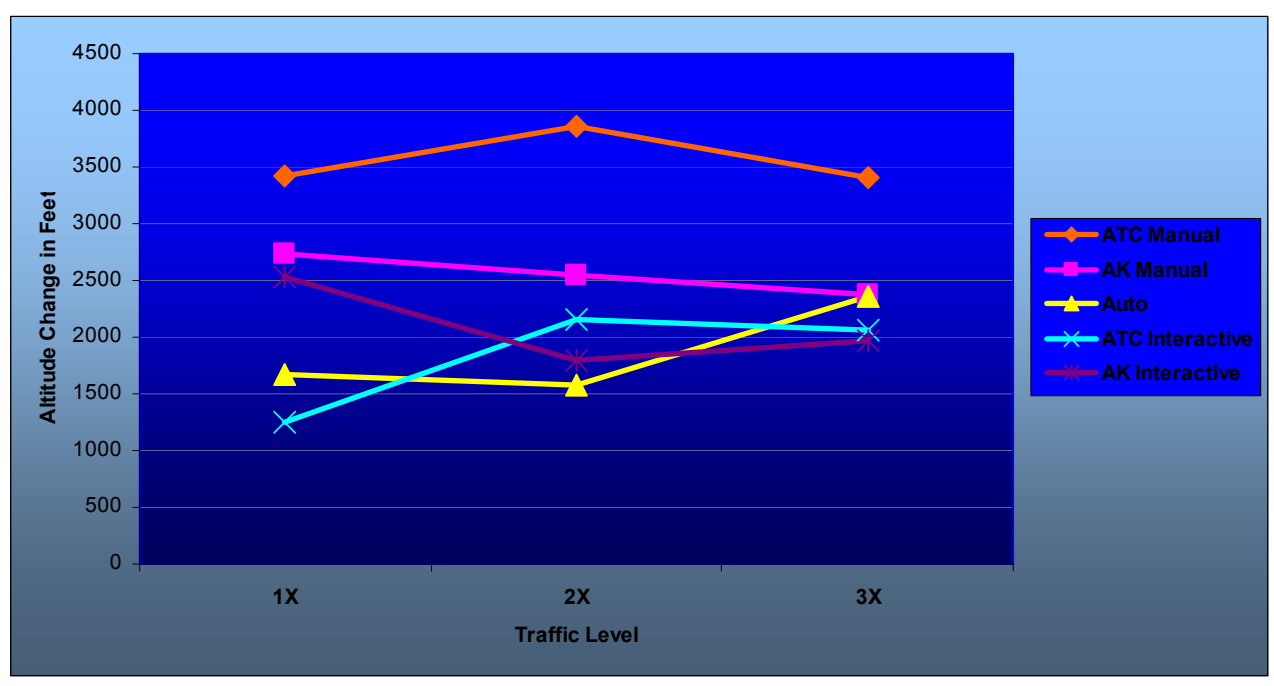

Figure 16. Average absolute altitude change per vertical trajectory change

Figures 17 and 18 show the results in a different format and across all participants. Figure 17 depicts the mean and standard variation of the average delay per trajectory change. There is very little difference between the $2 \mathrm{x}$ and the $3 x$ numbers. This finding is consistent with earlier fast-time research ${ }^{19}$. Recent fast-time research suggests that the difference between $2 \mathrm{x}$ and $3 \mathrm{x}$ may also depend on the particular airspace situation ${ }^{26}$. 


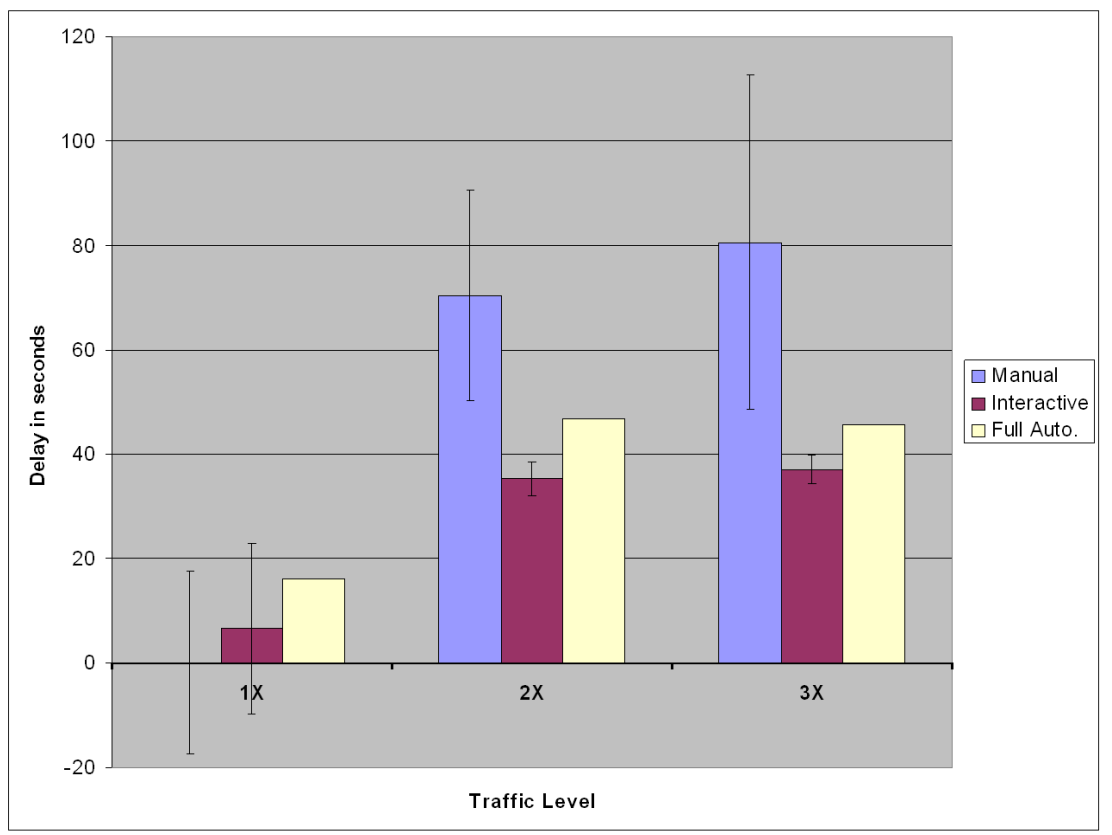

Figure 17. Delay per trajectory change (mean and standard deviation across all participants)

Figure 17 also suggests that the interactive conflict resolutions were more efficient than the automated resolutions. However, as discussed earlier in the strategy section and Figure 12, the interactive mode experienced more trajectory changes than the automated mode. This is reflected in the cumulative delay depicted in Figure 18. This chart shows how much total time traffic was delayed during the 30 minute runs at the various traffic densities and automation levels. The interactive mode appears somewhat more efficient than the automated mode in the $2 \mathrm{x}$ denisty, but almost identical at 3x. 2x manual was less efficient than the interactive or automated modes.

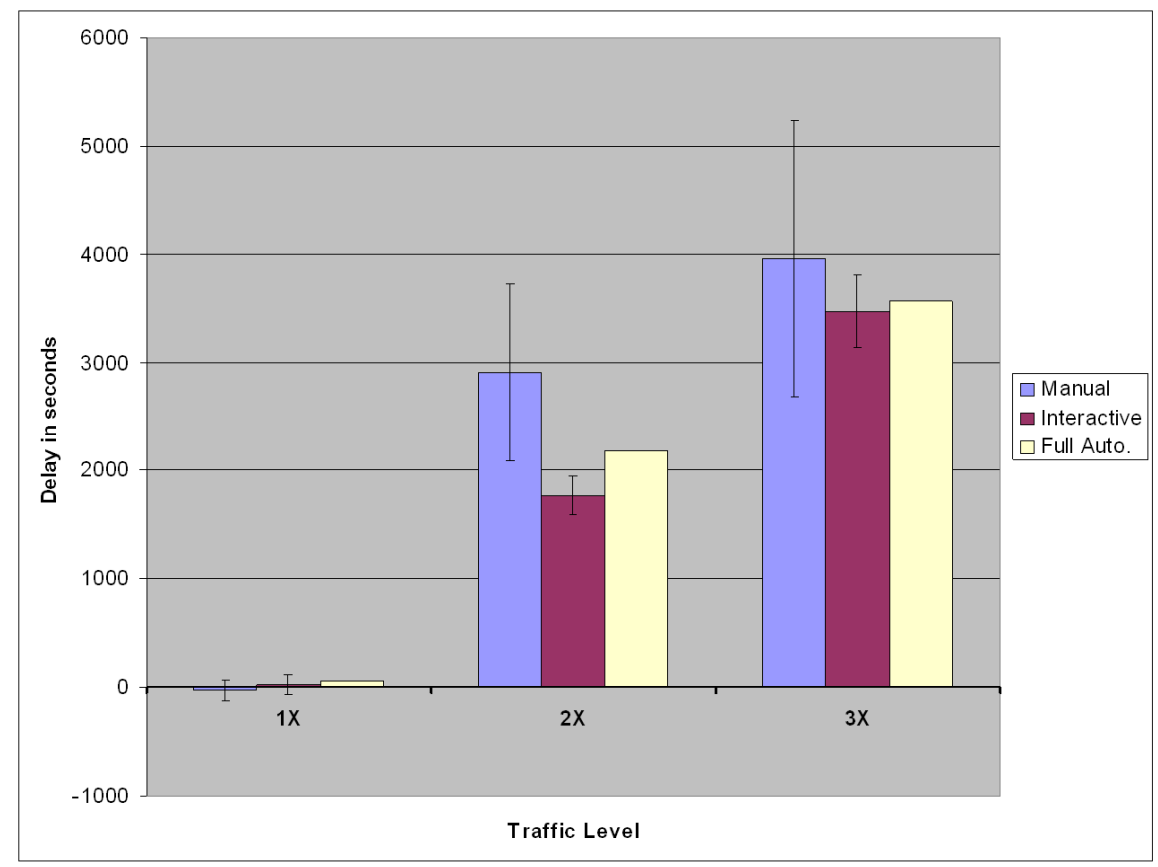

Figure 18. Cumulative delay (mean and standard deviation) across all participants

Interestingly, the cumulative delay that was imposed in the $3 \mathrm{x}$ density was almost identical across all conditions. Keeping in mind that only a subset of all detected conflicts was actually resolved in the $3 \mathrm{x}$ manual case, the $3 \mathrm{x}$ result is in line with the earlier observation that the primarily limiting factor in this environment is the time it takes to 
complete a certain amount of trajectory changes, which equates to imposing a certain amount of delay on the system.

\section{F. Discussion}

The results presented here show that the drastic paradigm shift in making the automation responsible for conflict detection and automating routine tasks pays off. With automated conflict detection and conflict resolution aids traffic densities of equipped aircraft can be raised significantly beyond today's levels. As long as conflict resolution is a manual process, the comfortable limit may be less than 2x. However, using the conflict resolution algorithm interactively raised this level even further. This was most apparent at the $3 x$ level of traffic where it was shown that operations are basically unthinkable in a manual trial planning mode. It was also shown, however, that more would need to be done for transitioning to $3 \mathrm{x}$ traffic. Having the controller in the loop on each trajectory change at $3 \mathrm{x}$ density appears to be exceeding the comfortable workload limit. Overall, the automated conflict resolution function was highly acceptable, especially to the air traffic controllers. Through participant feedback and observation of the runs and the collected data, potential improvements to the auto resolution logic were identified and planned for incorporation. The display design appeared straightforward, intuitive and in support of the task. This was supported by the fact that after only a few hours of training operators were able to work the positions effectively.

While these results are very encouraging it is also confirmed that with a less than perfect trajectory-based conflict detection function other means of safety assurance need to be in place in order to provide the required level of safety to assign the task of separation monitoring to the automation and move to higher traffic levels.

\section{Follow-on Research}

The study described in this paper was the first of several studies investigating fundamental questions of automated separation assurance operations. This study investigated the level of automation; the next experiments were aimed at mixed equipage operations, tactical safety assurance and off-nominal operations. As this paper is being finalized, data collection from the other two experiments is completed. The analysis is ongoing and results will be presented soon. An overview over these studies follows:

The question of whether and how mixed equipage will be accommodated in an automated separation assurance environment is important for separation assurance and airspace design considerations. To begin answering some of the basic questions in this area, an initial study on mixed operations was conducted in the AOL in April 2008. This study was sponsored and led by the dynamic airspace configuration element of NASA's airspace system program. The objective of the study was to identify the appropriate future airspace configuration in terms of whether or not it should be segregated or integrated to support mixed operations. This means examining if mixed equipage operations are feasible in the same airspace under varying levels of traffic densities (e.g., 1X, 2X, and 3X) and varying levels of equipage mix (i.e., increasing number of non-equipped aircraft). A detailed report on this study will be compiled once the data analysis has been concluded. In Prevot et al, $2008^{28}$ the design of the study and a few initial findings are presented.

The third initial human-in-the-loop part-task study on ground-based automated separation assurance focused on tactical separation assurance and off-nominal events. The main research question can be stated as "How do controllers, pilots and the automation interact in off-nominal situations and how can the system be safe under uncertainties and resulting imperfections in trajectory-based separation assurance?" This study was conducted jointly by the AOL and the Flight Deck Display Research Lab (FDDRL) at NASA Ames in July/August 2008 with participant pilots and controllers.

In this study the tactical separation assurance layer was integrated into the ground automation using a near-term conflict alerting function and the TSAFE conflict resolution module. The trajectory-based separation assurance layer was largely automated. The study investigated whether and how a certified professional controller can effectively supervise the automation, provide additional services, and resolve near-term conflicts with and without automated aids. The flight deck perspective was investigated in the same study with airline pilots. Data collection was finished on August 1, 2008. An overview over the study design is available $i^{28}$. Findings will be reported when the data analysis is complete. Initial observations and debrief discussions yielded generally very positive feedback and no major showstoppers were noticed. 


\section{Concluding Remarks}

An initial part-task evaluation of air traffic control operators interacting with ground-based separation assurance automation has yielded very positive results. Automated conflict detection has the potential to eliminate controller workload as the limiting factor in increasing sector capacity. The prototyped conflict resolution algorithm generates highly acceptable and efficient trajectory changes and appears capable of handling the anticipated growth in air traffic for NextGen. A tactical safety layer as well as procedures for handling off-nominal situations will be required, but were not part of the study discussed in this paper. The human-in-the-loop research on these aspects started in 2008. These experiments with pilots and controllers in the loop will provide more data necessary to determine the operational validity and safety of the concept of service provider-based automated separation assurance.

\section{Acknowledgments}

This research owes its success to many dedicated individuals at NASA Ames Research Center including Dr. Walter Johnson and the flight deck display research group, the AOL support staff, and the MACS development team. We sincerely appreciate the very fruitful close cooperation with Dr. Heinz Erzberger and his team in preparing and conducting the research, as well as the support of the separation assurance associate principal investigators, Dave McNally and Todd Farley and the NGATS Airspace Project leadership.

\section{References}

1. FAA, "Long Range Aerospace Forecasts Fiscal Years 2015, 2020, 2025, and 2030," FAA APO-03-3 , URL: http://api.hq.faa.gov/Forecast03/long03.pdf, 2003

2. Solomos, G., Urlass S., Bhadra, D., Kee, J., King,. E., McMahon, J., Swedish, W., Wells, M., "Capacity Needs in the National Airspace System: Analysis of Airport and Metropolitan Area Demand and Operational Capacity in the Future," Mitre Center for Advance Aviation System Development, McLean, VA., MP 04W0000109, May 2004.

3. JPDO, 2006 "Next Generation Air Transportation System", URL: http://www.jpdo.aero/factsheet.html

4. JPDO, 2006 "Concept of Operations for the Next Generation Air Transportation System", Draft version 0.2, July 24, 2006.

5. SESAR Consortium, Eurocontrol 2006 "Air Transport Framework, The Performance Targets D2", URL: http://www.eurocontrol.int/sesar/gallery/content/public/docs/DLM-0607-001-02-00a.pdf

6. Swenson H., Barhydt R. and Landis M. "NGATS ATM-Airspace Project Reference Material (External Release)". www.aeronautics.nasa.gov/nra_pdf/airspace_project_c1.pdf

7. Prevôt, T., Callantine, T. J., Homola, J., Lee, P., Mercer, J., Battiste, V., Johnson, W., Palmer E., \&Smith, N. (2007). "Air/Ground Simulation of Trajectory-Oriented Operations with Limited Delegation", Proceedings of the 7th USA/Europe Air Traffic Management Research and Development Seminar, Barcelona, Spain.

8. Prevot, T., N. Smith, E. Palmer, J. Mercer, P. Lee, J. Homola, T. Callantine, 2006, "The Airspace Operations Laboratory (AOL) at NASA Ames Research Center", AIAA-2006-6112, AIAA, Reston, VA.

9. Johnson W. and V. Battiste (2006) "NASA Ames Flight Deck Display Research Laboratory" URL: http://human-factors.arc.nasa.gov/ihh/cdti/index.html

10. Barhydt, R. and Kopardekar, P. (2005) "Joint NASA Ames/Langley Experimental Evaluation of Integrated AirGround Operations for En Route Free Maneuvering", 6th USA/Europe Air Traffic Management R\&D Seminar, Baltimore, MD, FAA and Eurocontrol.

11. Prevot T., Battiste V., Callantine T. Kopardekar P., Lee P., Mercer J., Palmer E., Smith N. (2005) "Integrated Air/Ground System: Trajectory-Oriented Air Traffic operations, Data Link Communication, and Airborne Separation Assistance" Air Traffic Control Quarterly Volume 13, Number 2 Special Issue on ASAS, pp. 201229, (Francis Casaux Editor)

12. McNally, B. D., S. Engelland, R. Bach, W. Chan, C. Brasil, C. Gong, J. Frey, D. Vincent, "Operational Evaluation of the Direct-To Controller Tool," 4th USA/Europe Air Traffic Management R\&D Seminar, Santa Fe, New Mexico, USA, December 3-7, 2001.

13. Callantine, T., P. Lee, J. Mercer, T. Prevôt, E. Palmer, 2005, "Simulation of Terminal-Area Flight Management System Arrivals with Airborne Spacing", Air Traffic Control Quarterly, Vol. 14, No. 1, pp. 47-67.

14. Barmore, B., T. Abbott, and K. Krishnamurthy, 2004, "Airborne-managed spacing in multiple arrival streams", Proceedings of the 24th International Congress of the Aeronautical Sciences, Yokohama, Japan. 
15. Corker, K., Liang, D., Lee, P., and Prevot, T. (2007). , "New Air Traffic Management Concepts Analysis Methodology: Application to a Multi-Sector Planner in US Airspace.", $7^{\text {th }}$ FAA/Eurocontrol R\&D Seminar, Barcelona, Spain.

16. Celio, J. C. and E. Smith, July 2007, "Performance-based Air Traffic Management: Evaluating Operational Acceptability," 7th USA/Europe ATM R\&D, Barcelona, Spain.

17. Rozen, N., July 2007, "Performance-based Air Traffic Management: Evaluation of En Route Benefits," 7th AIAA Aviation Technology, Integration, and Operations (ATIO) International Conference, Belfast, Northern Ireland.

18. Erzberger, H., 2004, “Transforming the NAS: The Next Generation Air Traffic Control System", 24th International Congress of the Aeronautical Sciences, Yokohama, Japan, August 2005.

19. Farley, T. and H. Erzberger (2007) FAST-TIME SIMULATION EVALUATION OF A CONFLICT RESOLUTION ALGORITHM UNDER HIGH AIR TRAFFIC DEMAND, $7^{\text {th }}$ FAA/Eurocontrol R\&D Seminar, Barcelona, Spain.

20. McNally, D. and C. Gong (2006) "Concept and Laboratory Analysis of Trajectory-Based Automation for Separation Assurance", AIAA 2006-6600, AIAA Guidance, Navigation, and Control Conference and Exhibit 21 - 24 August 2006, Keystone, Colorado

21. Muller, E. (2007) "Experimental Evaluation of an Integrated Datalink and Automation-Based Strategic Trajectory Concept", 7th AIAA Aviation Technology, Integration, and Operations (ATIO) International Conference, Belfast, Northern Ireland.

22. Prevot, T. (2002) Exploring the Many Perspectives of Distributed Air Traffic Management - The Multi Aircraft Control System MACS in S.Chatty, J. Hansman, and G. Boy (Eds.) Proceedings of the International Conference on Human-Computer Interaction in Aeronautics, HCI-Aero 2002 AAAI Press, Menlo Park, CA pp. 159-157

23. Prevot, T. and J. Mercer (2007) MACS: A Simulation Platform for Today's and Tomorrow's Air Traffic Operations, AIAA

24. P. Kopardekar, M. Jastrezebski, and T. Prevot (2008) "Complexity Measurement under Higher Traffic Densities and Higher Levels of Automation" AIAA 2008-, AIAA Guidance, Navigation, and Control Conference and Exhibit 18 - 21 August 2008, Honolulu, Hawaii

25. Kupfer, M., Farley, T., Chu, Y., Erzberger, H. (2008), "Automated Conflict Resolution - A Simulation-Based Sensitivity Study of Airspace and Demand," ICAS-2008-8.9.1, 26th International Congress of the Aeronautical Sciences (ICAS), Anchorage, Alaska, Sept 15-19, 2008

26. McNally, D., and D. Thipphavong. (2008), "Automated Separation Assurance in the Presence of Uncertainty," ICAS-2008-8.8.1, 26th International Congress of the Aeronautical Sciences (ICAS), Anchorage, Alaska, Sept $15-19,2008$

27. Homola, J. (2008) "Analysis of Human and Automated Conflict Resolution Capabilities at Varying Levels of Traffic Density". Master's thesis, San Jose State University, San Jose, California

28. Prevot, T., Homola J. and J. Mercer (2008) "Human-in-the-Loop Evaluation of Ground-Based Automated Separation Assurance for NextGen" ICAS 2008-11.4.5, 6th International Congress of the Aeronautical Sciences (ICAS), and AIAA-ATIO, Anchorage, Alaska, Sept 15-19, 2008 